\title{
Demanda Mediana por Serviços Públicos e Desempenho Eleitoral: Evidências do Modelo do Eleitor Mediano para os Municípios Brasileiros
}

\author{
- Rafael Terra de Menezes* - Carlos César Santejo Saiani ** \\ - Ana Carolina Pereira Zoghbi ${ }^{\star \star \star}$
}

\begin{abstract}
Resumo
O objetivo deste trabalho é testar empiricamente a validade do modelo do eleitor mediano para o caso brasileiro. O teste foi viabilizado pela possibilidade de reeleição, estabelecida em 1997 por meio da Emenda da Reeleição. Com informações municipais do Censo Populacional e do TSE para o ano de 2000, identificaram-se as cestas ofertadas por candidatos à reeleição como os gastos efetuados durante seus primeiros mandatos. Em seguida, estimou-se a demanda por serviços públicos locais. Relaxando a hipótese de informação perfeita dos candidatos em relação à demanda mediana, e impondo uma hipótese menos forte, de expectativas racionais, justificou-se a estimação de uma medida de erro de percepção dos candidatos à reeleição em relação à demanda mediana. Em seguida, estimou-se o impacto do módulo dessa medida sobre o desempenho eleitoral dos candidatos à reeleição usando modelos de seleção. $O$ resultado obtido sugere que o modelo do eleitor mediano é válido para os municípios brasileiros.
\end{abstract}

\section{Palavras-Chave}

demanda por serviços públicos, eleitor mediano, reeleição, modelos de seleção

\begin{abstract}
The aim of this work is to empirically test the validity of the median voter model for the Brazilian case. The test was made feasible by the possibility of reelection established in 1997 by the Reelection Amendment. With municipal information from the Demographic Census and from TSE for the year of 2000, we identified the bundle offered by candidates running for reelection as the expenditures realized during their first terms. Next, we estimated the demand for local public services. Relaxing the assumption of perfect information of candidates in relation to the median demand, and imposing a weaker hypothesis, of rational expectations, we justified the estimation of a measure of misperception of candidates for reelection in relation to median demand. Next, we estimated the impact of the module of this measure on the electoral performance of mayors incumbents using a selection model. The result suggests that the median voter model is valid for the case of Brazilian municipalities.
\end{abstract}

\section{Keywords}

demand for public services, median voter, reelection, selection models

\section{JEL Classification}

$\mathrm{H} 40, \mathrm{H} 41, \mathrm{H} 70$

\footnotetext{
+ Os autores agradecem a dois pareceristas anônimos por seus comentários. Quaisquer erros remanescentes são de responsabilidade dos autores.

* Doutorando em Economia (EESP-FGV). E-mail: rflterra@yahoo.com.br.

** Professor da Universidade Presbiteriana Mackenzie e Doutorando em Economia (EESP-FGV). E-mail: ssaiani@yahoo.com.br.

*** Doutora em Política e Economia do Setor Público (EAESP-FGV). E-mail: zoghbi80@yahoo.com.br.

Endereço para contato: Av. Deputado Emílio Carlos, 521, apt. 65A. Bairro do Limão - São Paulo - SP. CEP: 02721-000.

(Recebido em agosto de 2009. Aceito para publicação em março de 2010).
} 


\section{Introdução}

Desenvolvido inicialmente por Bowen (1943), Black (1948) e Donws (1957), o Modelo do Eleitor Mediano determina que, sob a hipótese de que as preferências dos eleitores apresentem "pico único", em um sistema eleitoral majoritário, os eleitores escolherão o candidato cuja cesta ofertada de bens e serviços públicos mais se aproxime da cesta demandada pelo eleitor mediano. Esse modelo é bastante razoável, mas poucos estudos se propuseram a testar empiricamente sua validade. Dada a definição sucinta desse modelo, uma alternativa de teste empírico, para verificar sua validade, deveria envolver a estimação da demanda representativa desse eleitor e o conhecimento das cestas ofertadas pelos candidatos.

Em relação às cestas que cada candidato oferta, deve-se notar que dificilmente seria possível mensurá-las, pois são cestas potenciais, não realizadas. Porém, há um caso especial em que isso é possível: quando o candidato já se encontra eleito e concorre à reeleição. Nesse caso, pode-se assumir que a cesta ofertada por ele é dada pelo montante e pelo direcionamento dos gastos realizados durante seu mandato, inclusive no ano eleitoral.

Já no que se refere à demanda representativa, Borcherding e Deacon (1972) e Bergstrom e Goodman (1973), em seus estudos seminais, propõem meios de estimá-la. Sob a hipótese de que a "mediana das quantidades demandadas seja igual à demanda do cidadão com renda mediana" e que "a quantidade mediana demandada seja igual à ofertada", conseguem identificar a demanda mediana local por bens públicos. A última hipótese é bastante restritiva, pois afirma que os políticos no poder sempre ofertam a cesta preferida pelo eleitor mediano, ou seja, têm informação perfeita. Porém, se isso fosse verdade, com a possibilidade de reeleição, dever-se-ia sempre observar os candidatos se reelegendo, o que não é o caso. Assim, essa hipótese, além de desproporcionalmente forte, restringe a realização de um teste empírico que busque analisar a possibilidade de punição em virtude de desvios da cesta ofertada pelos candidatos à reeleição em relação à cesta demandada pelo eleitor mediano.

Relaxando essa hipótese de informação perfeita dos candidatos à reeleição, e adotando uma hipótese mais branda, como expectativas racionais, é possível que haja erros de percepção não sistemáticos dos candidatos à reeleição em relação à demanda mediana. Assim, um teste empírico, para o modelo do eleitor mediano, seria possível para o caso brasileiro. Ressalta-se que, para o teste, seria indispensável verificar a possibilidade de reeleição, caso contrário, não haveria como mensurar nenhuma cesta ofertada a não ser por surveys com os candidatos à reeleição. 
Inman (1978) e Gramlich e Rubinfeld (1982) são alguns exemplos de trabalhos que buscam testar empiricamente a validade do modelo do eleitor mediano com dados de surveys nos Estados Unidos. Ambos encontram evidências favoráveis. Enquanto o primeiro conclui que famílias com a renda mediana exercem influência crucial na determinação do nível de gastos, o segundo mostra que a maior parte dos eleitores está satisfeita com a combinação de níveis de gastos e de impostos. Doi (1999), por outro lado, usando dados agregados, também encontra evidências favoráveis ao modelo para o caso de governos subnacionais japoneses.

Para o Brasil, não há trabalhos empíricos que busquem testar a validade do modelo do eleitor mediano na forma aqui proposta. Contudo, há trabalhos que estudam os determinantes da reeleição. A proposta deste trabalho se insere nessa literatura ao considerar a possibilidade de que a reeleição seja determinada, em parte, pelo sucesso do candidato à reeleição em atingir a demanda do eleitor mediano. De uma maneira geral, os estudos apontam outras variáveis como determinantes do sucesso nas urnas, tais como: (i) desempenho na primeira eleição; (ii) performance dos governantes no primeiro mandato - por exemplo, melhora dos indicadores de educação e saúde, aumento do acesso a serviços públicos, aumento do nível de emprego e da renda, entre outros -; (iii) características pessoais dos governantes - idade e escolaridade, por exemplo -; (iv) envolvimento dos governantes em escândalos e em crimes durante o primeiro mandato; (iv) condições políticas - partido, existência de concorrente com força política e apoio de outros governantes, por exemplo -; (vi) características da localidade - população, taxa de urbanização, região geográfica, entre outras -; (vii) gastos com a campanha eleitoral, e (vii) padrão dos gastos públicos - de acordo com o modelo de ciclos políticos/eleitorais. Como exemplos de estudos empíricos desse tipo para o caso brasileiro, pode-se citar Mendes (2004), Meneguin, Bugarin e Carvalho (2005) e Mendes e Rocha (2007). ${ }^{1}$

Como explicitado anteriormente, o objetivo deste artigo é testar a validade do modelo do eleitor mediano para os municípios brasileiros, buscando verificar o impacto dos desvios da cesta ofertada em relação à demanda mediana sobre o sucesso eleitoral (dado pela proporção de votos ou pela probabilidade de reeleição). Para isso, com algumas hipóteses descritas mais adiante, é possível estimar a demanda por serviços públicos locais (inclusive para diferentes funções de despesas) e obter

1 Outra parte da literatura tem como objetivo analisar o impacto da instituição da reeleição sobre diversos resultados políticos e econômicos. Nesses estudos, duas hipóteses básicas são confrontadas na tentativa de avaliar qual delas prevalece: (i) diante da possibilidade de reeleição, os governantes agiriam de forma oportunista, adotando políticas expansionistas para aumentar a probabilidade de se elegerem - de acordo com o modelo de ciclos políticos/eleitorais oportunístico -, ou (ii) a possibilidade de serem "punidos" na reeleição faria com que os governantes diminuíssem a utilização discricionária e meramente eleitoreira dos instrumentos de políticas públicas - de acordo com o modelo de controle eleitoral. Pode-se citar como exemplos de estudos empíricos desse tipo para o Brasil: Meneguin e Bugarin (2001) e Nakaguma e Bender (2004). 
uma medida de desvio ou erro de percepção dos candidatos à reeleição municipal em relação à demanda mediana. Em seguida, pode-se verificar o impacto da magnitude dessa medida de desvio sobre a proporção de votos do candidato e sobre a probabilidade de reeleição, utilizando modelos de seleção. Essa medida de "desvio" pode ser entendida também como um indicador de desempenho do candidato, o que justifica a inserção do trabalho proposto na literatura de reeleição mencionada acima. Por fim, impactos negativos desse indicador sobre a proporção de votos ou sobre a probabilidade de reeleição devem fornecer evidências favoráveis ao modelo do eleitor mediano.

Esse trabalho divide-se em cinco seções, incluindo esta introdução. Na segunda seção, é apresentada a estratégia do teste, ou seja: i) o modelo teórico de demanda do eleitor mediano e o modelo econométrico para estimar essa demanda; ii) as hipóteses que permitem estimar os erros de percepção dos candidatos à reeleição em relação à demanda mediana, que fazem com que as cestas ofertadas difiram das demandadas pelos eleitores medianos de cada localidade, e iii) os modelos econométricos de seleção para estimar o impacto desses desvios entre a cesta demanda e ofertada sobre o sucesso eleitoral dos candidatos à reeleição. Na terceira seção, são apresentadas as fontes de informação usadas para obter os dados necessários para a realização do teste empírico e as variáveis usadas nas estimações. Na quarta seção, são apresentados os resultados e, por fim, na quinta seção, encontram-se as considerações finais.

\section{Modelo Teórico e Estratégia de Estimação}

Primeiramente, é importante destacar que as estimações realizadas partem da suposição inicial de que candidatos a um primeiro mandato buscam atingir as preferências do eleitor mediano fornecendo informações sobre suas potenciais ofertas de cestas de bens e serviços públicos. Os candidatos à reeleição, por outro lado, podem tentar atingir as preferências do eleitor mediano ofertando as cestas que acreditam serem as mais próximas das demandadas durante seu mandato, o que inclui anos eleitorais. Assim, não se pode medir a cesta de bens públicos dos candidatos a um primeiro mandato, mas pode-se medir essa cesta para aqueles que estejam concorrendo à reeleição. Portanto, com algumas hipóteses apresentadas nas subseções seguintes, é possível testar empiricamente o modelo do eleitor mediano utilizando informações sobre os candidatos à reeleição municipal. 


\subsection{Identificação da Demanda do Eleitor Mediano}

A identificação da demanda do eleitor mediano fundamenta-se em hipóteses, que, consideradas em conjunto, constituem o equilíbrio de Bowen. De acordo com Bergstrom e Goodman (1973), essas hipóteses podem ser resumidas da seguinte forma: (i) o custo de provisão de uma determinada commodity fornecida por um município $j$ é constante e igual à $q_{j}$; (ii) cada consumidor $i$, do município $j$, paga uma fração do custo total de provisão - essa fração é uma função de sua renda, riqueza e outras características individuais e é independente do tamanho das despesas municipais e de suas preferências em relação à provisão dos serviços públicos -; (iii) cada consumidor $i$, de um município $j$, conhece seu tax price, e é capaz de determinar sua quantidade desejada para o município dado, que deve pagar a fração do total das despesas municipais - para isso, deve maximizar suas preferências sujeitas à restrição orçamentária individual -, e (iv) em cada município $j$, a quantidade fornecida de um bem público é igual à mediana das quantidades demandadas. Além disso, Bergstrom e Goodman (1973) supõem que: (v) a quantidade demandada mediana é igual à quantidade demandada pelo cidadão com renda mediana. Sob esse conjunto de hipóteses, pode-se proceder com a estratégia de identificação da demanda do eleitor mediano por serviços públicos locais.

Note, primeiramente, que o modelo do eleitor mediano é um modelo de escolha coletiva e o objetivo deste trabalho é justamente verificar se esse mecanismo de escolha é válido em alguma medida. Isso quer dizer que não incorremos no problema de inferência ecológica, de acordo com o qual a utilização de dados agregados, para inferir comportamentos individuais, produziria estimativas enviesadas. ${ }^{2}$ Resumidamente, tentamos fazer inferências sobre o comportamento coletivo, usando variáveis características do eleitor mediano, variáveis sobre os níveis de preço dos bens privados e públicos, características do município e variáveis agregadas ao nível municipal, que devem refletir os gostos do eleitor mediano por bens públicos. ${ }^{3}$

Dessa forma, considere o eleitor mediano de um município $j$ que busca maximizar sua preferência $u_{m}^{j}\left(c_{m}^{j}, g^{j}\right)$ sujeita à restrição orçamentária: ${ }^{4}$

2 Ver King (1997) para um detalhamento maior do problema de inferência ecológica, e CanêdoPinheiro (2009) para uma discussão mais resumida.

3 É importante destacar que, desde o início da década de 1980, estudos como o de Bergstrom, Rubinfeld e Shapiro (1982), Gramlich e Rubinfeld (1982) e Rubinfeld, Shapiro e Roberts (1987) buscaram estimar a demanda por bens públicos com dados das preferências reveladas dos entrevistados. Esse tipo informação seria ideal, mas nunca foi feita uma pesquisa parecida para o Brasil. De qualquer forma, estes autores encontram resultados similares à demanda do eleitor mediano baseados em dados de despesas com bens públicos.

4 Este modelo é semelhante ao utilizado por Mendes e Sousa (2006), diferindo apenas em alguns detalhes e no relaxamento da hipótese "iv". Isso não resulta em diferenças em termos dos parâmetros estimados, mas permite interpretar o termo de erro associado à estimação da demanda de forma distinta, o que tem implicações importantes para este trabalho. 


$$
p^{j} c_{m}^{j}+\left(t^{j}+\bar{\theta}\right) b_{m}^{j} \leq y_{m}^{j}
$$

em que o subscrito $m$ denota o eleitor mediano; $c_{m}^{j}$ é a quantidade consumida de bens privados; $g^{j}$ é a quantidade constante de serviços públicos que cada habitante da localidade $j$ consome; $p^{j}$ é o nível geral de preços de bens privados no município $j ; b_{m}^{j}$ é a base tributária do eleitor mediano; $t^{j}$ é a alíquota média de imposto local; $\bar{\theta}$ é a alíquota média nacional constante de imposto ${ }^{5}$ e $y_{m}^{j}$ é a renda individual. A alíquota local $t^{j}$ é determinada pela restrição orçamentária do município:

$$
q^{j} G^{j}=Z^{j}+t^{j} B^{j}
$$

que, rearranjando, resulta em:

$$
t^{j}=\frac{q^{j} G^{j}-Z^{j}}{B^{j}}
$$

em que $G^{j}$ é a quantidade de bens e serviços públicos; $q^{j}$ é o custo médio constante; $Z^{j}$ é o total de transferências recebidas pelo município, e $B^{j}$ é a base tributária total da localidade. Pode-se expressar a quantidade de bens e serviços públicos alternativamente por $G^{j}=n^{\gamma} g^{j}$, em que $n$ representa o total da população do município $j$ e $\gamma$ representa o grau de congestionamento do bem público. Se $\gamma$ for igual a um, os bens (ou serviços) públicos são puramente privados (exclusivos) e, se for igual a zero, são bens públicos puros (não exclusivos e não rivais). ${ }^{6}$ Para valores intermediários de $\gamma$, verifica-se características mistas de bens públicos e privados. Já valores superiores à unidade indicam que os bens públicos são supercongestionados. ${ }^{7}$

A alíquota nacional $\bar{\theta}$ é determinada pela restrição orçamentária do governo central:

5 Por simplicidade, supõe-se, nesse modelo, que exista somente um nível superior de governo, o Governo Central.

6 Também conhecidos na literatura como bens públicos puros samuelsonianos. Samuelson (1954) define bens públicos como bens que podem ser consumidos coletivamente, e ressalta a dificuldade de identificar as preferências por esse tipo de bens, já que os consumidores não têm incentivos para revelar suas preferências como fazem no mercado de bens privados.

7 O grau de congestionamento indica, de certa forma, a divisibilidade de um bem. Um bem público puro não é congestionado e todos podem consumir a quantidade total ofertada. Bens públicos com grau de congestionamento entre zero e um indicam que cada indivíduo pode consumir uma quantidade menor do que o total ofertado. Bens públicos com grau de congestionamento igual a um têm características de bens privados, são exclusivos. Por fim, bens supercongestionados, que apresentam grau de congestionamento maior do que um, podem surgir devido às deseconomias de escala. 


$$
D+\sum_{j=1}^{J} Z^{j}=\bar{\theta} \sum_{j=1}^{J} B^{j}
$$

em que $D$ é o gasto total do Governo Central; $\sum_{j=1}^{J} Z^{j}$ é o total de transferências aos municípios e $\sum_{j=1}^{J} B^{j}$, a base tributária total do país. ${ }^{8}$ Inserindo (3) na restrição orçamentária (1) e, por simplicidade, mantendo a alíquota $\bar{\theta}$ em sua forma reduzida (já que é a mesma para todos os municípios), manipulações algébricas resultam na restrição modificada:

$$
y_{M}^{j}+z^{j}\left(\frac{b_{m}^{j}}{\overline{b^{j}}}\right)-\bar{\theta} b_{m}^{j}=p^{j} c_{m}^{j}+q^{j} n^{\gamma-1}\left(\frac{b_{m}^{j}}{\overline{b^{j}}}\right) g^{j}
$$

em que o termo do lado esquerdo de (5) representa a renda líquida, ${ }^{9}$ podendo ser denotado por $y_{m}^{j L}$. Os únicos termos novos são $\overline{b^{j}}$ e $z^{j}$, que representam, respectivamente, a base tributária média e as transferências por pessoa na localidade $j$. Adicionalmente, normalizando (5) pelo nível de preços do setor privado $p^{j}$, obtémse a seguinte expressão reduzida:

$$
\frac{y_{m}^{j L}}{p^{j}}=c_{m}^{j}+\frac{q^{j}}{p^{j}} n^{\gamma-1}\left(\frac{b_{m}^{j}}{\overline{b^{j}}}\right) g^{j}
$$

A função demanda por bens públicos se baseia em Borcherding e Deacon (1972) e Bergstrom e Goodman (1973), e é dada por:

$$
g^{j}=A\left(\tau_{m} q^{j} n^{\gamma}\right)^{\eta}\left(y_{m}^{j}\right)^{\epsilon}
$$

a qual é log-linear na renda e no tax price, dado por $\tau_{m}^{j} q^{j} n^{\gamma}=n^{\gamma-1}\left(\frac{b_{m}^{j}}{\overline{b^{j}}}\right) q^{j}$. Essa forma funcional, no entanto, não pode ser racionalizada por uma função utilidade direta, mas pode ser racionalizada por uma função utilidade indireta, que pode ser encontrada por meio da teoria da Dualidade. A atratividade dessa forma funcional advém do fato de ser econometricamente tratável, fato que determinou sua popularidade na literatura específica. ${ }^{10}$

A hipótese "iv" será relaxada, o que equivale a assumir que os dirigentes no poder não têm informação perfeita. Ao invés, supõe-se que a demanda mediana não é

8 Em outras palavras, a equação (4) representa a igualdade entre dispêndios e receitas.

9 A renda líquida, nesse caso, é dada pela renda individual total mais a parcela de transferências recebida pelo indivíduo $i$, menos o imposto pago ao Governo Central.

10 Ver Borcherding e Deacon (1972), Bergstrom e Goodman (1973), Doi (1999), Sanz e Velázquez (2002) e Mendes e Sousa (2006). 
diretamente observável pelos agentes, mas estes têm expectativas racionais em relação à demanda mediana. Assim, em um período de tempo suficientemente longo, os dirigentes no poder não cometerão erros sistemáticos ao tentarem ofertar a quantidade mediana de bens e serviços públicos demandados, ou seja:

$$
E\left[g_{t}^{j}-E\left[g_{t}^{j} \mid \Omega_{\mathrm{t}}^{\mathrm{j}}\right]\right]=0
$$

em que $g_{t}^{j}$ é a demanda mediana por bens e serviços públicos, e $E\left[g_{t}^{j} \mid \Omega_{t}^{j}\right]$ é a expectativa do candidato à reeleição do município $j$ em relação à demanda mediana com base no conjunto informação disponível em $t, \Omega_{\mathrm{t}}^{\mathrm{j}}$, e, portanto, consiste no nível efetivamente ofertado de bens e serviços públicos. Note que o fato de a demanda mediana não ser diretamente observável pelo candidato à reeleição permite que $g_{t}^{j}$ e $E\left[g_{t}^{j} \mid \Omega_{\mathrm{t}}^{\mathrm{j}}\right]$ possam diferir em um dado período.

Dessa forma, a demanda do eleitor mediano e a oferta efetiva (dada pela expectativa do candidato à reeleição em relação à demanda mediana), a cada período, podem diferir por um termo multiplicativo $v^{j}$, associado à incapacidade do representante municipal em fornecer exatamente a quantidade que iguala a oferta e a demanda com base no conjunto de informações disponíveis no período. Denotando a oferta $E\left[g_{t}^{j} \mid \Omega_{\mathrm{t}}^{\mathrm{j}}\right]$ por $g^{j^{*}}$, tem-se, então, em um dado período:

$$
g^{j^{*}}=g^{j} v^{j}
$$

Portanto, os determinantes desse erro devem estar relacionados principalmente a problemas de informação dos candidatos à reeleição. ${ }^{11,12}$ Destaca-se ainda que a relação entre a quantidade efetivamente ofertada per capita de bens públicos $g^{j *} \mathrm{e}$ o gasto médio por pessoa $e^{j}$ é dada por: ${ }^{13}$

$$
g^{j^{*}} q^{j}=\frac{G^{j^{*}} q^{j}}{n^{\gamma}}=\frac{E^{j}}{n^{\gamma}}=\frac{e^{j}}{n^{\gamma-1}}
$$

Assim, substituindo o tax price e a renda líquida normalizados pelo nível de preços $p^{j}$, e a quantidade per capita efetiva ofertada de bens públicos $g^{j^{*}}$ em termos de gasto médio por pessoa $e^{j}$ em (7), resulta em:

$$
e^{j}=A\left(\frac{q^{j}}{p^{j}} n^{\gamma-1} \frac{b_{m}^{j}}{\overline{b^{j}}}\right)^{\eta}\left(\frac{y_{m}^{j L}}{p^{j}}\right)^{\epsilon} n^{\gamma-1} q^{j} v^{j}
$$

11 Se $v^{j}=1 \Rightarrow g^{j^{*}}=g^{j}$. Se $0 \leq v^{j}<1 \Rightarrow g^{j^{*}}<g^{j}$ Se $v^{j}>1 \Rightarrow g^{j^{*}}>g^{j}$.

12 Note que $\operatorname{Cov}\left(g^{j}, v^{j}\right)=0$ por hipótese.

13 As variáveis representadas por letras maiúsculas não estão em termos per capita. 
Por fim, pode-se agregar, multiplicativamente do lado direito de (11), um vetor $\varnothing^{j}=\prod_{k=1}^{K}\left(x_{k}^{j}\right)^{\beta_{k}}$ de variáveis explicativas e um termo de erro $\varepsilon^{j}$, referente a fatores não observáveis, que exercem influência sobre a demanda do eleitor mediano. ${ }^{14}$ Tomando o logaritmo em ambos os lados dessa expressão, resulta em:

$$
\ln e^{j^{*}}=\ln A+(\gamma-1)(\eta+1) \ln n^{j}+\eta \ln \frac{b_{m}^{j}}{\overline{b^{j}}}+\in \ln y_{m}^{j L}+(1+\eta) \ln q^{j}-(\eta+\epsilon) \ln p^{j}+\beta_{k} \sum_{k=6}^{K} x_{k}^{j}+\ln v^{j} \varepsilon^{j}
$$

O coeficiente da população, $\alpha=(\gamma-1)(\eta+1)$, fornece, juntamente com a elasticidadepreço do bem público $\eta$, o parâmetro de congestionamento, dado por $\gamma=\frac{\alpha+\eta+1}{\eta+1}$.

O termo de erro $\ln v^{j} \varepsilon^{j}$ é crucial para a estratégia de teste aqui proposta, pois suas estimativas (os resíduos) contêm informações sobre a incapacidade dos dirigentes municipais de atender à demanda do eleitor mediano. Mais adiante, será visto como essa informação ajudará no teste empírico do modelo.

É importante ressaltar algumas dificuldades para estimar a equação (12). Primeiramente, não há dados disponíveis por municípios referentes às variáveis $q^{j}$ e $p^{j}$ (respectivamente, níveis de preços de bens e serviços públicos e privados). Bergstrom, Rubinfeld e Shapiro (1982) lidam com esse problema utilizando como proxies os salários médios nos setores público e privado. ${ }^{15}$ Assim, o mesmo deverá ser feito neste trabalho.

Outra dificuldade refere-se à medida para a base tributária. Estudos sobre a demanda local por bens públicos nos Estados Unidos costumam utilizar o valor da propriedade do eleitor mediano como medida de base tributária. Isso é bastante razoável tendo em vista que, naquele país, grande parte dos gastos locais é financiada com impostos sobre a propriedade. No caso do Brasil, os impostos locais não têm a mesma importância no orçamento da maioria dos municípios. Desse modo, seguindo o procedimento de Mendes e Sousa (2006), é mais razoável usar as rendas mediana e média do município $j$ como medidas das bases tributárias mediana $b_{m}^{j}$ e média $\overline{b^{j}}$, necessárias para obtenção de $\frac{b_{m}^{j}}{\overline{b^{j}}}$ e, portanto, para a estimação de (12).

14 Isso equivale a assumir uma tecnologia de consumo Hicks-neutra. Ver Edwards (1990) e Mendes (2005, p. 83).

15 O objetivo dos autores era estimar a demanda por gastos em educação. Para isso, buscaram proxies para os níveis de preços educacionais públicos e privados, que eram variáveis explicativas no modelo. A solução adotada pelos autores consistiu em utilizar o salário médio dos professores de escolas públicas e privadas do distrito. 
Finalmente, supondo que se verifiquem as hipóteses de rank pleno e de que o termo composto de erro $\ln v^{j} \varepsilon^{j}$ seja ortogonal aos regressores de (12), ${ }^{16}$ pode-se estimar consistentemente a demanda do eleitor mediano por Mínimos Quadrados Ordinários, ${ }^{17}$ e também os resíduos, nos quais reside especial interesse, já que os mesmos contêm informações (dadas por $v^{j}$ ) sobre a imprecisão dos dirigentes locais em atenderem à demanda do eleitor mediano.

\subsection{Erros de Percepção dos Candidatos à Reeleição em Relação à Demanda Mediana}

De acordo com o modelo do eleitor mediano, os candidatos com maior probabilidade de se elegerem são aqueles cuja cesta ofertada de bens e serviços se aproxima mais das preferências do eleitor mediano. Em um contexto em que há possibilidade de reeleição, supõe-se, então, que a cesta de bens ofertada pelo candidato a um segundo mandato é percebida pelos eleitores como idêntica à cesta ofertada até então. Portanto, é razoável supor também que a magnitude do erro de percepção dos candidatos à reeleição em um primeiro mandato, em relação à demanda mediana, influencie negativamente a proporção de votos recebidos e a probabilidade de reeleição.

De fato, não se conhece as magnitudes dos erros de percepção $v^{j}$. Pode-se, no entanto, estimar o resíduo de (12):

$$
\widehat{U}^{j}=\widehat{\ln v^{j} \varepsilon^{j}}=\widehat{\ln v^{j}}+\widehat{\ln \varepsilon^{j}}=\widehat{\ln v^{j}}+\varepsilon_{0}^{j}
$$

em que a ênfase denota o valor estimado. Porém, o interesse reside na magnitude de $\widehat{\ln v^{j}}$, que não pode ser estimada separadamente. Uma hipótese forte seria a de que não há fatores não observáveis $\varepsilon_{0}^{j}$ que exerçam influência sobre a demanda e, portanto, $\widehat{U}^{j}=\widehat{\ln v^{j}}$.

Outra possibilidade, mais razoável, seria supor que $\widehat{U}^{j}=\widehat{\ln v^{j}}+\varepsilon_{0}^{j}$ possa ser considerada uma variável medida com erro. Assim, para obter uma medida de magnitude do erro de percepção do candidato à reeleição, pode-se tomar seu módulo. ${ }^{18}$ Para efeito de simplificação, essa variável estimada é denominada "mod $\widehat{U}$ ", tal que:

$$
\bmod \widehat{U}=\left|\widehat{U}^{j}\right|
$$

16 Ressalta-se também que dado $\ln v^{j} \varepsilon^{j}=\ln v^{j}+\ln \varepsilon^{j}$, por hipótese, os dois termos do lado esquerdo não são correlacionados com os regressores e não são correlacionados entre si.

17 Supondo, adicionalmente, que não haja autocorrelação espacial, como admitem Mendes e Sousa (2006), e nem viés de Tiebout, como admitem Gramlich e Rubinfeld (1982) e Rubinfeld, Shapiro e Roberts (1987).

18 Também se pode elevar essa variável ao quadrado sem mudanças expressivas nos resultados encontrados. 
Nesse caso, supondo que a variável mod $\widehat{U}$ contenha erro de medida, em um modelo de regressão linear, no qual essa variável é uma das explicativas, seu coeficiente será inconsistente; mas o viés, nesse caso, se dará em direção a zero, ou seja, será "atenuado". Resultados não significativos podem estar subestimados, em módulo, de modo que não se pode rejeitar a hipótese de que o coeficiente seja igual a zero. $\mathrm{Se}$, no entanto, o interesse residir somente no sinal do coeficiente, estimativas que produzam coeficientes significativos cumprem seu papel, mesmo que viesadas em direção a zero.

Ressalta-se, no entanto, que o efeito de variáveis explicativas medidas com erro em modelos não lineares são menos conhecidos na literatura. Mesmo assim, Edgerton e Jochumzen (2003) mostram, por meio de simulações, que, em modelos de escolha binária (Probit, por exemplo), o coeficiente de uma variável explicativa, medida com erro, também sofre atenuação. Como será visto na próxima subseção, serão usados métodos não lineares de estimação, nos quais a variável mod $\widehat{U}$ deverá entrar como explicativa, portanto, é possível que haja atenuação.

Dessa forma, supondo que $\widehat{U}^{j}=\widehat{\ln v^{j}}$ ou $\widehat{U}^{j}=\widehat{\ln v^{j}}+\varepsilon_{0}$, espera-se encontrar o verdadeiro sinal do coeficiente da regressão da proporção de votos e da probabilidade de reeleição sobre variável mod $\widehat{U}$, ou seja, espera-se estimar o efeito da magnitude do erro de percepção em relação à demanda mediana sobre o resultado eleitoral. Para isso, serão usados modelos de seleção de Heckman, já que os candidatos se autosselecionam para concorrerem às eleições. ${ }^{19}$

\subsection{Modelos de Seleção: Estimação do Desempenho na Reeleição}

Doi (1999) realiza, para o caso das eleições dos governos subnacionais japoneses, um teste parecido com o proposto neste trabalho, utilizando o módulo do resíduo para estimar o impacto sobre a probabilidade de reeleição por meio do método Probit. Contudo, o autor não considera o problema de viés de seleção implícito ao processo de reeleição. Nesse sentido, é razoável supor que o prefeito só se candidata à reeleição se ele acreditar que tem uma boa probabilidade de se reeleger, configurando, assim, um viés de autosseleção. ${ }^{20}$ Dessa forma, o estudo dos determinantes da reeleição, sem considerar o problema de autosseleção, levaria a resultados enviesados.

Mendes e Rocha (2004), apesar de não abordarem a questão da demanda do eleitor mediano, alertam para o problema de viés de seleção, ao estimarem determinantes

19 Ver Mendes e Rocha (2007).

20 Sobre esse assunto, ver Heckman (1979). 
da proporção de $\operatorname{votos}^{21}$ e da probabilidade de reeleição para prefeitos, utilizando dados referentes ao ano de 2000. Os autores utilizam o Modelo de Seleção de Heckman para o caso da variável dependente ser contínua e o método Probit com seleção para o caso da variável dependente ser binária. Assim, conseguem estimar consistentemente os determinantes da proporção de votos e da probabilidade de reeleição.

Ressalta-se também, nesse caso, que o problema de inferência ecológica não deve estar presente, pois procuramos avaliar os determinantes do sucesso eleitoral não de um candidato, mas de todos aqueles que se candidataram à reeleição. É um modelo geral de determinação do sucesso de candidatos a um segundo mandato. Não há razão para modelar o comportamento individual neste caso, isto é, não se pode inferir que pessoas com características específicas sejam favoráveis à reeleição dos prefeitos em geral. Como será visto mais adiante, todas as variáveis explicativas dos modelos (15-16) e (18-19) se referem às características políticas do governo do prefeito candidato à reeleição ou às próprias características dos prefeitos. Não há variáveis individuais agregadas, nem suporte teórico para incluí-las.

Propõe-se, então, a seguinte especificação para a equação referente à variável dependente contínua proporção de votos do candidato à reeleição no município $j$ (modelo 1):

$$
\begin{aligned}
& \ln \left(\text { proporção devotos }^{j}\right)=X_{1}^{j} \beta+\varphi \bmod \hat{U}^{j}+u^{j} \\
& \text { candidato }^{j}=1\left[X_{2}^{j} \alpha+\varepsilon^{j}>0\right]
\end{aligned}
$$

A expressão (15) é a equação de interesse que fornecerá o parâmetro $\varphi$ referente à variável $\bmod \widehat{U}$, e $X_{1}^{j}$ é um vetor linha de variáveis explicativas referentes ao município $j$ ou ao candidato dessa localidade. A expressão (16) consiste na equação de seleção, de modo que a variável dependente dessa equação, candidato $^{j}$, é sempre observada e assume valores iguais a zero se o prefeito no poder não for candidato à reeleição, e igual a um se for candidato. O vetor linha de variáveis explicativas, $X_{2}^{j}$, determina a candidatura, devendo incluir ao menos uma variável excluída de (15) - neste artigo, essa variável é a proporção de candidatos à reeleição na mesma microrregião, que será apresentada mais adiante. A variável dependente em (15), proporção de $\operatorname{votos}^{j}$, só é observada se candidato $^{j}=1$. O método de estimação para identificar (15) é o método de Heckman (ou Heckit), em que:

21 Na verdade, utilizam uma variável denominada força, que consiste na proporção recebida de votos pelo candidato à reeleição do município $j$ multiplicada pela quantidade de candidatos ao cargo de prefeito. 


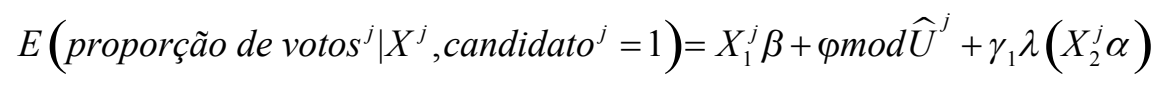

no qual $\lambda(\cdot)$ é a razão inversa de Mills. Ressalta-se que, sob algumas condições, o método de Heckman permite estimar consistentemente os parâmetros do modelo e, em especial, o parâmetro $\varphi$ da variável $\bmod \widehat{U}$.

Na realidade, a literatura aponta distribuições mais adequadas à modelagem econométrica de variáveis dependentes em proporções do que modelos normais, como os estimados por OLS (ou Heckit). De fato, o Estimador de Máxima Verossimilhança baseado na distribuição Beta, doravante denominado BMLE, é comumente apontado como a melhor solução para modelar taxas e proporções - ver Ferrari e Cribari-Neto (2004), Paolino (2001), Abensur, Cribari-Neto e Menezes (2007) e Kieschnick e McCullogh (2003) - ante a estimadores baseados em outras possíveis distribuições.

No entanto, Paolino (2001), ao analisar dados de diversos estudos, destaca que "isso não quer dizer que (...) todas as análises em Economia Política devam ser feitas usando o BMLE" (p. 345). O autor, replicando as estimações de Atkeson (1998, apud PAOLINO, 2001) e Lowery e Gray (1998, apud PAOLINO, 2001), conclui que a utilização deste estimador não fez diferença alguma comparativamente aos resultados obtidos pelos métodos normais (OLS, principalmente). Ainda de acordo com o autor, em ambos os casos, os dados "(...) não tinham valores próximos aos limites do intervalo e eram razoavelmente simetricamente distribuídos. Nessas circunstâncias, a análise apresentada (...) não sugere que o BMLE irá necessariamente contribuir muito além do que foi obtido pelos métodos normais" (p. 345).

Tendo isso em mente, procedeu-se com a construção de um histograma dos dados sobre a proporção de votos recebidos por candidatos à reeleição municipal em 2000, com a finalidade de avaliar o grau de simetria da distribuição empírica. Para isso, foi inserida no histograma uma função distribuição Normal sobreposta, que serviu como padrão para a avaliação.

Como se pode observar no painel A da Figura 1, a distribuição empírica da proporção de votos dos candidatos à reeleição municipal é bastante simétrica e, de fato, apesar de não ser igual a uma distribuição normal, ${ }^{22}$ é bem próxima desta, com valores um pouco mais centrados em torno da média. Calculando a assimetria e a curtose da distribuição empírica da proporção de votos dos candidatos, foram encontrados valores iguais a $-0,18$ e 3,71 , respectivamente. Esses valores são bem

22 O teste de Shapiro e Francia (1972) rejeita que a distribuição empírica seja igual a uma Normal, mas o valor da estatística é baixo, igual a 4,228. 
próximos aos da distribuição Normal (iguais a 0 e 3, nessa ordem), especialmente considerando o fato de que os dados são extraídos da natureza, e não resultantes de médias amostrais com reposição. Ademais, nota-se que não há concentrações de observações próximas aos limites do intervalo de 0 a 1 . No painel $\mathrm{B}$, encontra-se um gráfico no qual quanto mais próximo da reta de $45^{\circ}$ a linha cheia estiver, mais próxima a distribuição empírica será da Normal. ${ }^{23}$ Como se pode notar, o grau de sobreposição é grande, confirmando que os dados sobre proporção de votos formam uma distribuição simétrica e pouco achatada.

Painel A

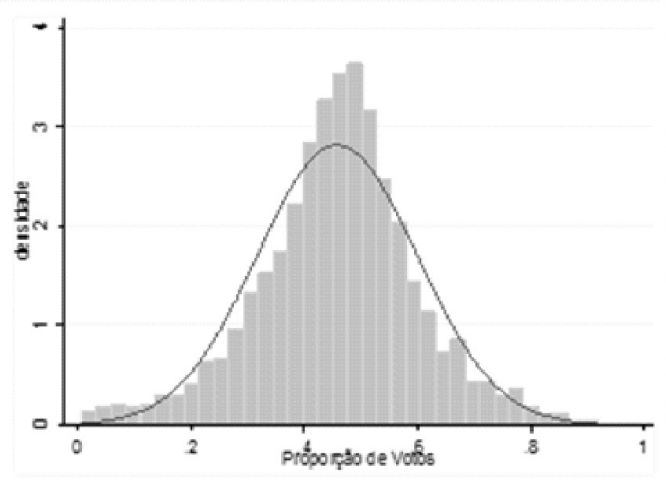

Painel B

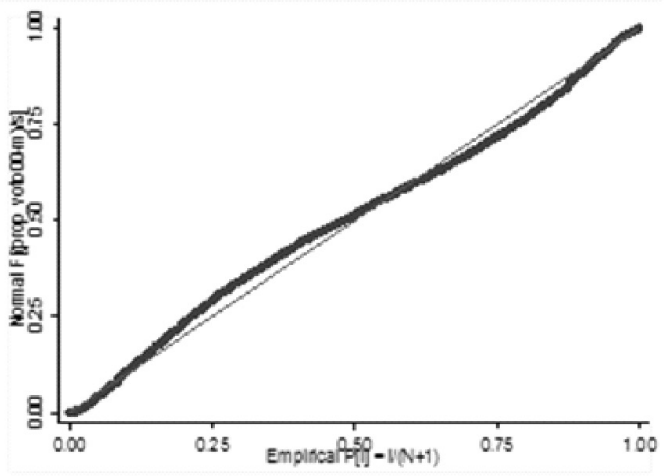

Figura 1 - Distribuição Empírica da Proporção de Votos dos Candidatos à Reeleição em 2000

Fonte: Elaboração própria com dados do TSE de 2000.

Por fim, considerando a existência do problema de autosseleção neste trabalho, a utilização de um estimador baseado na distribuição Beta (ou em alguma outra distribuição) exigiria um grande esforço algébrico e computacional para desenvolver um tipo híbrido de estimador, o que, além de não ser o foco deste estudo, melhoraria muito pouco a confiabilidade dos resultados. Portanto, o Modelo de Seleção de Heckman parece ser mais vantajoso, tendo em vista a estrutura dos dados usados neste trabalho.

No caso da estimação do impacto do mod $\widehat{U}$ sobre a probabilidade de reeleição, deve-se utilizar o método Probit com Seleção. As especificações das equações principais e de seleção, nesse caso (modelo 2), são:

23 Esse gráfico, denominado Probability-Probability Plot (ou PP-Plot), representa, no eixo x, a função acumulada da distribuição empírica e, no eixo y, a função acumulada da distribuição Normal. 


$$
\begin{aligned}
& \text { reeleito }^{j}=1\left[X_{1}^{j} \beta+\varphi \bmod \widehat{U}^{j}+u^{j}>0\right] \\
& \text { candidato }^{j}=1\left[X_{2}^{j} \alpha+v^{j}>0\right]
\end{aligned}
$$

em que a variável reeleito ${ }^{j}$ assume valor igual a 0 se o prefeito não for reeleito e 1 se for reeleito. Assim, essa variável só é observada se candidato $^{j}=1$. Os coeficientes, apesar de estarem denotados pelo mesmo símbolo (para simplificação), serão diferentes, uma vez que a equação (18) tem a variável binária dependente reeleito ${ }^{j}$ em contraposição à variável contínua proporção de votos $^{j}$ em (15).

Apesar de as equações (15) e (18) serem diferentes, o intuito delas é o mesmo: testar o modelo do eleitor mediano. Um sinal negativo e significativo do coeficiente da variável mod $\widehat{U}$ implica que os resultados empíricos dão suporte a esse modelo. É importante ressaltar, mais uma vez, que o coeficiente $\varphi$ deve ser interpretado como o impacto do tamanho do erro de percepção em relação à demanda mediana sobre o desempenho eleitoral (maior proporção de votos obtidos ou maior probabilidade de reeleição).

Deve-se apontar, também, que as variáveis contínuas foram utilizadas em suas formas logarítmicas. Isso significa que os coeficientes de variáveis contínuas, na equação 15 , podem ser interpretados como elasticidades. Na equação 18 , por outro lado, referente ao método Probit com seleção, os coeficientes não tem significado direto e, para uma interpretação com significado econômico, devem ser calculados os efeitos marginais.

Por fim, dada a possibilidade de atenuação nos coeficientes dos modelos Heckit e Probit com seleção em virtude de erros de medida, para encontrar o verdadeiro valor do coeficiente de $\bmod \widehat{U}$, seria necessário usar alguma variável instrumental, que, a princípio, não parece estar facilmente disponível. Este instrumento deveria estar correlacionado com o termo $\widehat{\ln v^{j}}$ de $\bmod \widehat{U}$ e não correlacionado com o termo de erro aleatório das equações 15 e 18. Dado que essa componente $\left(\widehat{\ln v^{j}}\right)$ deve estar associada à informação acerca da demanda mediana disponível a cada candidato, a obtenção de um instrumento não é algo simples, e pode ser encarada como parte de uma agenda futura de pesquisa. Assim, o interesse neste artigo reside no sinal e na significância dos coeficientes $\varphi$ 's referente à variável $\bmod U$, pois isto deve ser suficiente para a validade dos testes propostos. 


\section{Dados}

As variáveis utilizadas nas estimações da demanda e dos modelos de seleção se referem ao ano de 2000. Nesse ano, dois fatores contribuíram para a construção de um banco de dados mais adequado à realização do teste proposto. Primeiramente, $\mathrm{o}$ ano de 2000 foi o momento de realização do último Censo Demográfico do IBGE, o que permitiu a obtenção de dados para a estimação da demanda mediana. Ademais, coincidentemente, e providencialmente, nesse ano ocorreram eleições municipais, que permitiram pela primeira vez a candidatura à reeleição em cargos executivos municipais. Assim, conforme apontam Mendes e Rocha (2007), todos os prefeitos eleitos em 1996, que não sofressem algum impedimento legal, estariam aptos a concorrer à reeleição no pleito em 2000, e estes já sabiam disso nos momentos iniciais de seus primeiros mandatos, podendo definir suas estratégias de governo visando a essa possibilidade. As informações eleitorais usadas nas estimações dos modelos de seleção são provenientes do Tribunal Superior Eleitoral (TSE), sendo exceções duas variáveis explicativas, referentes a municípios novos (variável Município_novo) e municípios divididos (variável Município_dividido), obtidas no IBGE. 


\begin{tabular}{|c|c|}
\hline Variáveis dependentes & Descrição \\
\hline Despesa Corrente & despesa total excluindo a despesa de capital; \\
\hline Despesa Bens Meritórios & $\begin{array}{l}\text { somatório das despesas com educação, cultura, habitação, urbanismo, saúde e sanea- } \\
\text { mento básico; }\end{array}$ \\
\hline $\begin{array}{l}\text { Despesa Bens Públicos } \\
\text { Puros }\end{array}$ & somatório das despesas com legislativo, judiciário, planejamento e segurança pública; \\
\hline Despesa Bens Econômicos & $\begin{array}{l}\text { somatório das despesas com agricultura, indústria, comércio, transporte, desenvolvi- } \\
\text { mento regional, energia, recursos minerais, comunicações e outras; }\end{array}$ \\
\hline Despesa Bem-Estar & gastos com assistência e previdência; \\
\hline Variáveis independentes & Descrição \\
\hline renda_med & $\begin{array}{l}\text { renda domiciliar per capita mediana. Dada a dificuldade em estimar exatamente a } \\
\text { alíquota nacional, supõe-se que não haja redistribuição via transferências, ou seja, o } \\
\text { montante recebido de transferências e o imposto nacional pagos são iguais. Portanto, } \\
\text { a renda mediana é usada como uma proxy da renda mediana líquida original no mo- } \\
\text { delo de demanda; }\end{array}$ \\
\hline tax_price & $\begin{array}{l}\text { de acordo com Mendes e Sousa (2006), é definido como a razão entre as rendas } \\
\text { mediana e média. Ressalta-se que a expressão original para essa variável envolvia } \\
\text { também o nível de preços de bens públicos e o termo referente à população do municí- } \\
\text { pio, mas, após tomar o logaritmo desse termo composto, pode-se estimar os coeficien- } \\
\text { tes de cada variável separadamente e ainda assim identificar a elasticidade-preço da } \\
\text { demanda por bem público; }\end{array}$ \\
\hline população & população de cada município; \\
\hline salário_privado & $\begin{array}{l}\text { salário médio do setor privado, utilizado como uma proxy para o nível de preços do } \\
\text { setor privado, conforme Bergstrom, Rubinfeld e Shapiro (1982); }\end{array}$ \\
\hline salário_público & $\begin{array}{l}\text { salário médio do setor público, utilizado como uma proxy para o nível de preços do } \\
\text { setor público, também conforme Bergstrom, Rubinfeld e Shapiro (1982); }\end{array}$ \\
\hline densidade & densidade demográfica de cada município; \\
\hline capitais & $\begin{array}{l}\text { dummy que assume valor um se o município for uma capital estadual e zero caso } \\
\text { contrário; }\end{array}$ \\
\hline tx_ocup_domic & proporção de pessoas ocupadas no domicílio com 18 anos ou mais; \\
\hline res_município & porcentual de pessoas que residem no município há mais de cinco anos; \\
\hline não_branco & porcentual de indivíduos não-brancos vivendo no município; \\
\hline idade_17 & porcentual de pessoas com menos de 18 anos; \\
\hline idade_65 & porcentual de pessoas com mais de 65 anos; \\
\hline anos_est_25 & média de anos de estudo entre pessoas com mais de 25 anos; \\
\hline variação da população & variação porcentual da população de cada município entre 1991 e 2000; \\
\hline dummies estaduais & dummies para cada Estado, sendo São Paulo o Estado excluído para comparação. \\
\hline
\end{tabular}

\section{Quadro 1 - Descrição das Variáveis Usadas nas Estimações das Demandas Medianas}

Fonte: Finbra/STN (variáveis referentes à despesa), IPEADATA (densidade demográfica) e Censo Demográfico de 2000/IBGE (demais variáveis). 
Os dados referentes aos gastos públicos locais são provenientes da Finbra, base de dados com informações fiscais anuais dos Estados e municípios brasileiros, disponibilizado pela Secretaria do Tesouro Nacional. Além do gasto corrente, foram considerados também outros tipos de despesas como variáveis dependentes, agrupadas de acordo com características comuns dos bens fornecidos. Com isso, foi possível verificar se o modelo para a demanda é razoavelmente estável de acordo com o grupo de bens considerados e estimar o parâmetro de congestionamento para cada grupo de bens, o que é particularmente interessante. Também interessa verificar se os erros de percepção em relação à demanda mediana são mais ou menos punidos no processo eleitoral de acordo com os tipos de bens considerados. A classificação dos tipos de bens foi feita de acordo com Oxley e Martin (1991), e consiste em separar as despesas referentes a bens meritórios, puros, serviços econômicos e bem-estar. ${ }^{24}$ Procurou-se adaptar a classificação dos autores de acordo com as informações disponíveis para os municípios brasileiros, mas algumas diferenças são inevitáveis em virtude da forma como estão agregados os dados da Finbra.

No Quadro 1, encontram-se as descrições das variáveis dependentes e independentes usadas na estimação da demanda mediana. Já, no Quadro 2, encontra-se a descrição das variáveis dependentes e independentes usadas para estimar os modelos de seleção para avaliar os determinantes do desempenho eleitoral.

24 Ver a descrição no Quadro 1. 


\begin{tabular}{|c|c|}
\hline Variáveis dependentes & Descrição \\
\hline Prop00 & $\begin{array}{l}\text { razão entre o número de votos obtidos pelo candidato e o número total de votos no muni- } \\
\text { cípio em 2000; }\end{array}$ \\
\hline Reel00 & $\begin{array}{l}\text { variável binária que assume o valor um se o prefeito foi reeleito em } 2000 \text { e zero caso } \\
\text { contrário; }\end{array}$ \\
\hline Cand00 & $\begin{array}{l}\text { variável binária que assume valor um se o prefeito eleito em } 1996 \text { se candidatou à reelei- } \\
\text { ção em } 2000 \text { e zero caso contrário. }\end{array}$ \\
\hline Variáveis independentes & Descrição \\
\hline Prop96 & $\begin{array}{l}\text { razão entre o número de votos obtido pelo candidato e o número total de votos no muni- } \\
\text { cípio em 1996; }\end{array}$ \\
\hline Partido_presidente & $\begin{array}{l}\text { dummy que assume valor um se o prefeito disputou a reeleição em } 2000 \text { pelo partido do } \\
\text { Presidente da República e zero caso contrário; }\end{array}$ \\
\hline Partido_adv_presidente & $\begin{array}{l}\text { dummy que assume o valor um se o prefeito disputou a reeleição em } 2000 \text { contra um } \\
\text { adversário pertencente ao partido do presidente e zero caso contrário; }\end{array}$ \\
\hline Partido_governador & $\begin{array}{l}\text { dummy que assume o valor um se o prefeito disputou a reeleição em } 2000 \text { pelo partido } \\
\text { do governador de seu respectivo Estado e zero caso contrário; }\end{array}$ \\
\hline Partido_adv_governador & $\begin{array}{l}\text { dummy que assume o valor um se o prefeito disputou a reeleição em } 2000 \text { pelo partido } \\
\text { que foi, dois anos antes, segundo colocado nas eleições para governador de seu respec- } \\
\text { tivo Estado e zero caso contrário; }\end{array}$ \\
\hline Município_novo & $\begin{array}{l}\text { dummy que assume o valor um se o candidato disputou a eleição em um município cria- } \\
\text { do entre } 1993 \text { e } 1996 \text { - primeira eleição para prefeito em } 1996 \text { - e zero caso contrário; }\end{array}$ \\
\hline Município_dividido & $\begin{array}{l}\text { dummy que assume o valor um se o candidato disputou a eleição em um município que } \\
\text { perdeu parte de seu território durante o mandato do prefeito eleito em } 1996 \text { - de } 1997 \text { a } \\
2000 \text { - e zero caso contrário; }\end{array}$ \\
\hline Reeleitos_microrregião & $\begin{array}{l}\text { proporção de municípios pertencentes à mesma microrregião do município de referência } \\
\text { nos quais o prefeito foi reeleito em 2000; }\end{array}$ \\
\hline Candidato_reel_microrr & $\begin{array}{l}\text { proporção de municípios pertencentes à mesma microrregião do município de referência, } \\
\text { nos quais o prefeito foi candidato à reeleição em } 2000 \text { - essa é a variável que será utili- } \\
\text { zada apenas para explicar a candidatura; }\end{array}$ \\
\hline Idade_candidato 00 & idade do candidato em 2000; \\
\hline Idade_média00 & idade média dos candidatos a prefeito no respectivo município em 2000; \\
\hline Competição & número de candidatos por vaga; \\
\hline Fracionalização & $\begin{array}{l}\text { dada pela expressão } 1-\sum_{(i=1)}^{I} v_{i}^{2} \text {, em que } v_{i} \text { é a participação do iésimo partido no total } \\
\text { de vagas na Assembléia Legislativa; }\end{array}$ \\
\hline $\bmod \widehat{U}$ _ "tipo de despesa" & $\begin{array}{l}\text { representa o módulo dos resíduos da estimação da equação (12). Para cada variável } \\
\text { dependentes (despesa total, despesa corrente, bens meritórios, bens puros, serviços } \\
\text { econômicos e bem-estar), foi obtida uma variável mod } \widehat{U} \text { diferente, sendo que cada uma } \\
\text { delas é utilizada para estimar as equações (15) e (18). }\end{array}$ \\
\hline
\end{tabular}

\section{Quadro 2 - Descrição das Variáveis Usadas nas Estimações dos Modelos de Seleção}

Fonte: IBGE (variáveis Município_novo e Município_dividido), Estimativas ( $\bmod \widehat{U}^{j}$ _tipo de despesa") e Tribunal Superior Eleitoral (demais variáveìis). 
Nas estimações da demanda e dos modelos de seleção, todas as variáveis contínuas foram usadas em suas formas logarítmicas. Nas Tabelas 1 e 2, encontram-se as estatísticas descritivas das variáveis dependentes e independentes usadas para estimar as demandas (Tabela 1) e os modelos de seleção (Tabela 2), todas em valores absolutos (ao invés dos logaritmos). Na Tabela 2, pode-se notar que há dados eleitorais para 5.401 municípios. Nestes, $65 \%$ (ou 3.521) dos prefeitos disputaram a reeleição em 2000 , dentre os quais $58 \%$ foram reeleitos (2.044).

\section{Tabela 1 - Estatísticas Descritivas das Variáveis Usadas nas Estimações das Demandas Medianas}

\begin{tabular}{lcrrrr}
\hline Variável / Estatísticas & Obs & \multicolumn{1}{c}{ Média } & Desvio Padrão & Mínimo & Máximo \\
\hline renda_med & 5510 & 113,482 & 59,525 & 0,000 & 580,000 \\
tax_price & 5510 & 0,686 & 0,100 & 0,000 & 1,351 \\
população & 5510 & 30837 & 186713 & 795 & 10406116 \\
renda_privada & 5510 & 364,560 & 172,690 & 70,303 & 1835,549 \\
renda_pública & 5495 & 391,764 & 216,335 & 65,843 & 5699,764 \\
densidade & 5510 & 97,975 & 533,490 & 0,132 & 12915,980 \\
urbanização & 5509 & 0,588 & 0,233 & 0,016 & 1,000 \\
tx_ocup_domic & 5177 & 0,510 & 0,103 & 0,120 & 0,854 \\
res_município & 5177 & 0,891 & 0,066 & 0,321 & 1,000 \\
não_branco & 5177 & 0,457 & 0,255 & 0,000 & 0,993 \\
anos_est_25 & 5510 & 4,040 & 1,301 & 0,604 & 9,686 \\
idade_17 & 5177 & 0,379 & 0,059 & 0,216 & 0,613 \\
idade_65 & 5177 & 0,065 & 0,020 & 0,007 & 0,165 \\
var_pop_91_00 & 5177 & 0,111 & $-0,240$ & 0,516 & 3,440 \\
Despesa Corrente & 5174 & 470,44 & 992,97 & 0,280 & $55.317,31$ \\
Bens Meritórios & 5174 & 319,48 & 548,33 & 0,130 & $33.550,82$ \\
Bens Públicos Puros & 5174 & 128,67 & 423,61 & 0,000 & $22.255,74$ \\
Serviços Econômicos & 5174 & 61,78 & 81,21 & 0,000 & $2.931,04$ \\
Bem-Estar & 5174 & 36,11 & 117,88 & 0,000 & $6.753,24$ \\
\hline Fonte: Finbra/STN & & & & &
\end{tabular}

Fonte: Finbra/STN (variáveis referentes à despesa), IPEADATA (densidade demográfica) e Censo Demográfico de 2000/IBGE (demais variáveis).

Devido ao interesse principal do artigo se concentrar na avaliação do impacto do atendimento da demanda do eleitor mediano sobre o desempenho eleitoral de um prefeito candidato à reeleição, implicitamente, assume-se que apenas uma dimensão de performance dos prefeitos candidatos seja relevante. No entanto, a literatura especializada aponta diversas variáveis como determinantes do resultado em uma eleição ou da própria decisão de candidatura. Porém, no presente trabalho, algumas variáveis não disponíveis tiveram que ser deixadas de fora, como idade dos prefeitos que não se candidataram à reeleição, gastos de campanha e existência de processos criminais envolvendo os prefeitos. Dessa forma, para a validade das estimativas deste trabalho, supõe-se que essas variáveis omitidas não estejam correlacionadas com os regressores. 
Tabela 2 - Estatísticas Descritivas das Variáveis Usadas nas Estimações dos Modelos de Seleção

\begin{tabular}{|c|c|c|c|c|c|}
\hline Variável / Estatísticas & Obs & Média & Desvio Padrão & Mínimo & Máximo \\
\hline Prop00 & 3555 & 0,458 & 0,141 & 0,006 & 0,919 \\
\hline Reel00 & 3521 & 0,581 & 0,494 & 0,000 & 1,000 \\
\hline cand 00 & 5401 & 0,660 & 0,474 & 0,000 & 1,000 \\
\hline Prop96 & 5401 & 0,513 & 0,102 & 0,053 & 0,920 \\
\hline Partido_presidente & 5401 & 0,196 & 0,397 & 0,000 & 1,000 \\
\hline Partido_adv_presidente & 5401 & 0,207 & 0,405 & 0,000 & 1,000 \\
\hline Partido_governador & 5349 & 0,279 & 0,449 & 0,000 & 1,000 \\
\hline Partido_adv_governador & 5349 & 0,180 & 0,385 & 0,000 & 1,000 \\
\hline Município_novo & 5401 & 0,093 & 0,290 & 0,000 & 1,000 \\
\hline Reeleitos_microrregião & 5328 & 0,384 & 0,175 & 0,000 & 1,000 \\
\hline Idade_média00 & 5382 & 47,759 & 6,381 & 27,000 & 76,000 \\
\hline Idade_candidato 00 & 3605 & 49,333 & 9,273 & 24,000 & 83,000 \\
\hline Município_dividido & 5401 & 0,009 & 0,095 & 0,000 & 1,000 \\
\hline Competição & 5094 & 4,804 & 3,060 & 1,000 & 26,048 \\
\hline Fracionalização & 5242 & 0,696 & 0,125 & 0,000 & 1,000 \\
\hline Candidato_reel_microrr & 5401 & 0,660 & 0,185 & 0,000 & 1,000 \\
\hline $\bmod \widehat{U}$ Desp corr & 5158 & 0,213 & 0,337 & 0,000 & 7,097 \\
\hline mod $\widehat{U}{ }_{-}^{-}$Desp_merit & 5158 & 0,243 & 0,350 & 0,000 & 7,199 \\
\hline mod $\widehat{U} \_$Desp_bens_puros & 5157 & 0,323 & 0,392 & 0,000 & 7,294 \\
\hline mod $\widehat{U} \_D e s p \_b e n s \_e c o n$ & 5097 & 0,637 & 0,663 & 0,000 & 8,086 \\
\hline $\bmod \widehat{U}$ Desp bem estar & 5084 & 0,583 & 0,576 & 0,000 & 9,219 \\
\hline
\end{tabular}

Fonte: IBGE (variáveis Município_novo e Município_dividido), Estimativas (mod $\widehat{U}$ "tipo de despesa") e Tribunal Superior Eleitoral (demais variáveis).

\section{Resultados do Teste Empírico para o Modelo do Eleitor Mediano}

$\mathrm{Na}$ Tabela 3, encontram-se as estimativas por OLS com desvios padrão robustos das demandas medianas por bens públicos, utilizando as variáveis dependentes Despesa Corrente, Despesa Bens Meritórios, Despesa Bens Públicos Puros, Despesa Bens Econômicos e Despesa Bem-Estar. Em geral, os coeficientes obtidos apresentaram os sinais esperados, especialmente para as principais variáveis do modelo. As variáveis contínuas estão representadas por seus logaritmos, permitindo interpretar os coeficientes como elasticidades.

As elasticidades-renda (referentes a variável renda_med) foram positivas, indicando que os bens públicos possuem características de bens normais. As elasticidadespreço, dadas pelos coeficientes do tax_price baseado em Mendes e Sousa (2006), foram negativas, o que era esperado, dado que um aumento no preço de bens públicos deve levar a uma diminuição da demanda. As elasticidades populacionais foram negativas, indicando que quanto maior a população menor deve ser o gasto por ha- 
bitante. As variáveis proxies dos níveis de preços público e privado, salário_público e salário_privado, também apresentaram sinais coerentes com o modelo teórico em (11). Um aumento no nível de preços públicos aumenta o dispêndio, enquanto o aumento no nível de preços do setor privado causa redução desse dispêndio.

\section{Tabela 3 - Resultados das Estimações por OLS das Equações de Demanda do Eleitor Mediano}

\begin{tabular}{|c|c|c|c|c|c|}
\hline Vars Indep|Vars Dep & $\begin{array}{l}\text { Despesa } \\
\text { Corrente }\end{array}$ & $\begin{array}{c}\text { Despesa Bens } \\
\text { Meritórios }\end{array}$ & $\begin{array}{l}\text { Despesa Bens } \\
\text { Públ. Puros }\end{array}$ & $\begin{array}{c}\text { Despesa Bens } \\
\text { Econômicos }\end{array}$ & $\begin{array}{c}\text { Despesa } \\
\text { Bem-Estar }\end{array}$ \\
\hline renda_med & $\begin{array}{l}0,609^{\mathrm{a}} \\
(0,071)\end{array}$ & $\begin{array}{l}0,599^{\mathrm{a}} \\
(0,077)\end{array}$ & $\begin{array}{l}0,696^{\mathrm{a}} \\
(0,092)\end{array}$ & $\begin{array}{r}0,683^{\mathrm{a}} \\
(0,163)\end{array}$ & $\begin{array}{l}0,486^{\mathrm{a}} \\
(0,151)\end{array}$ \\
\hline tax_price & $\begin{array}{l}-0,342^{\mathrm{a}} \\
(0,080)\end{array}$ & $\begin{array}{l}-0,320^{\mathrm{a}} \\
(0,086)\end{array}$ & $\begin{array}{l}-0,383^{\mathrm{a}} \\
(0,100)\end{array}$ & $\begin{array}{l}-0,745^{\mathrm{a}} \\
(0,181)\end{array}$ & $\begin{array}{l}-0,444^{\mathrm{a}} \\
(0,167)\end{array}$ \\
\hline população & $\begin{array}{l}-0,280^{\mathrm{a}} \\
(0,012)\end{array}$ & $\begin{array}{l}-0,259^{\mathrm{a}} \\
(0,012)\end{array}$ & $\begin{array}{l}-0,344^{\mathrm{a}} \\
(0,014)\end{array}$ & $\begin{array}{l}-0,315^{\mathrm{a}} \\
(0,022)\end{array}$ & $\begin{array}{l}-0,242^{\mathrm{a}} \\
(0,019)\end{array}$ \\
\hline renda_privada & $\begin{array}{l}-0,148^{\mathrm{a}} \\
(0,048)\end{array}$ & $\begin{array}{l}-0,134^{\mathrm{a}} \\
(0,051)\end{array}$ & $\begin{array}{l}-0,204^{\mathrm{a}} \\
(0,062)\end{array}$ & $\begin{array}{l}-0,208^{\mathrm{b}} \\
(0,103)\end{array}$ & $\begin{array}{l}-0,186^{\mathrm{c}} \\
(0,106)\end{array}$ \\
\hline renda_pública & $\begin{array}{l}0,080^{\mathrm{a}} \\
(0,022)\end{array}$ & $\begin{array}{l}0,070^{\mathrm{a}} \\
(0,023)\end{array}$ & $\begin{array}{l}0,104^{\mathrm{a}} \\
(0,026)\end{array}$ & $\begin{array}{r}0,082^{\mathrm{b}} \\
(0,042)\end{array}$ & $\begin{array}{r}0,053 \\
(0,037)\end{array}$ \\
\hline capital & $\begin{array}{l}0,922^{\mathrm{a}} \\
(0,078)\end{array}$ & $\begin{array}{l}0,887^{\mathrm{a}} \\
(0,102)\end{array}$ & $\begin{array}{l}0,846^{\mathrm{a}} \\
(0,099)\end{array}$ & $\begin{array}{l}1,591^{\mathrm{a}} \\
(0,185)\end{array}$ & $\begin{array}{l}1,164^{\mathrm{a}} \\
(0,179)\end{array}$ \\
\hline densidade & $\begin{array}{l}-0,031^{\mathrm{a}} \\
(0,007)\end{array}$ & $\begin{array}{l}-0,024^{\mathrm{a}} \\
(0,008)\end{array}$ & $\begin{array}{l}-0,022^{b} \\
(0,009)\end{array}$ & $\begin{array}{l}-0,091^{a} \\
(0,018)\end{array}$ & $\begin{array}{l}-0,045^{\mathrm{a}} \\
(0,015)\end{array}$ \\
\hline urbanização & $\begin{array}{l}-0,005 \\
(0,015)\end{array}$ & $\begin{array}{r}0,006 \\
(0,016)\end{array}$ & $\begin{array}{l}0,044^{b} \\
(0,021)\end{array}$ & $\begin{array}{l}-0,360^{\mathrm{a}} \\
(0,041)\end{array}$ & $\begin{array}{l}0,185^{\mathrm{a}} \\
(0,036)\end{array}$ \\
\hline idade_65 & $\begin{array}{l}-0,300^{\mathrm{a}} \\
(0,032)\end{array}$ & $\begin{array}{l}-0,351^{\mathrm{a}} \\
(0,032)\end{array}$ & $\begin{array}{l}-0,361^{\mathrm{a}} \\
(0,041)\end{array}$ & $\begin{array}{l}-0,128 \\
(0,079)\end{array}$ & $\begin{array}{l}-0,190^{\mathrm{a}} \\
(0,067)\end{array}$ \\
\hline idade_17 & $\begin{array}{r}-0,084 \\
(0,108)\end{array}$ & $\begin{array}{l}-0,079 \\
(0,113)\end{array}$ & $\begin{array}{r}-0,108 \\
(0,139)\end{array}$ & $\begin{array}{l}-0,503^{6} \\
(0,253)\end{array}$ & $\begin{array}{l}-0,500^{6} \\
(0,222)\end{array}$ \\
\hline não_branco & $\begin{array}{l}0,046^{\mathrm{a}} \\
(0,013)\end{array}$ & $\begin{array}{l}0,043^{\mathrm{a}} \\
(0,014)\end{array}$ & $\begin{array}{r}0,070^{\mathrm{a}} \\
(0,017)\end{array}$ & $\begin{array}{l}-0,050^{b} \\
(0,024)\end{array}$ & $\begin{array}{l}0,114^{a} \\
(0,029)\end{array}$ \\
\hline res_município & $\begin{array}{l}-0,045 \\
(0,115)\end{array}$ & $\begin{array}{r}0,022 \\
(0,125)\end{array}$ & $\begin{array}{l}-0,246^{\mathrm{C}} \\
(0,145)\end{array}$ & $\begin{array}{l}-0,618^{\mathrm{a}} \\
(0,230)\end{array}$ & $\begin{array}{c}0,527^{b} \\
(0,229)\end{array}$ \\
\hline tx_ocup_domic & $\begin{array}{l}-0,314^{a} \\
(0,053)\end{array}$ & $\begin{array}{l}-0,276^{\mathrm{a}} \\
(0,057)\end{array}$ & $\begin{array}{l}-0,466^{\mathrm{a}} \\
(0,067)\end{array}$ & $\begin{array}{l}-0,177 \\
(0,114)\end{array}$ & $\begin{array}{l}-0,268^{\mathrm{b}} \\
(0,114)\end{array}$ \\
\hline anos_est_25 & $\begin{array}{l}0,095^{6} \\
(0,045)\end{array}$ & $\begin{array}{l}-0,005 \\
(0,049)\end{array}$ & $\begin{array}{l}0,251^{\mathrm{a}} \\
(0,057)\end{array}$ & $\begin{array}{l}-0,057 \\
(0,105)\end{array}$ & $\begin{array}{l}0,188^{\mathrm{C}} \\
(0,098)\end{array}$ \\
\hline var_pop_91_00 & $\begin{array}{l}-0,076^{a} \\
(0,027)\end{array}$ & $\begin{array}{l}-0,005 \\
(0,029)\end{array}$ & $\begin{array}{l}-0,123^{\mathrm{a}} \\
(0,038)\end{array}$ & $\begin{array}{r}-0,102 \\
(0,075)\end{array}$ & $\begin{array}{l}-0,216^{\mathrm{a}} \\
(0,064)\end{array}$ \\
\hline Constante & $\begin{array}{l}5,183^{\mathrm{a}} \\
(0,228)\end{array}$ & $\begin{array}{l}4,707^{\mathrm{a}} \\
(0,237)\end{array}$ & $\begin{array}{l}3,474^{\mathrm{a}} \\
(0,284)\end{array}$ & $\begin{array}{l}2,992^{\mathrm{a}} \\
(0,487)\end{array}$ & $\begin{array}{l}3,244^{\mathrm{a}} \\
(0,443)\end{array}$ \\
\hline Dummy UF & $\operatorname{sim}$ & $\operatorname{sim}$ & sim & $\operatorname{sim}$ & $\operatorname{sim}$ \\
\hline $\begin{array}{l}\text { R-squared } \\
\mathrm{N}\end{array}$ & $\begin{array}{l}0,462 \\
5.158\end{array}$ & $\begin{array}{l}0,361 \\
5.158\end{array}$ & $\begin{array}{l}0,429 \\
5.157\end{array}$ & $\begin{array}{l}0,444 \\
5.097\end{array}$ & $\begin{array}{l}0,313 \\
5.084\end{array}$ \\
\hline $\begin{array}{l}\text { Parâmetro de Con- } \\
\text { gestionamento }\end{array}$ & $\begin{array}{l}0,574^{\mathrm{a}} \\
(0,055)\end{array}$ & $\begin{array}{l}0,619^{a} \\
(0,052)\end{array}$ & $\begin{array}{l}0,443^{\mathrm{a}} \\
(0,095)\end{array}$ & $\begin{array}{l}-0,236 \\
(0,897)\end{array}$ & $\begin{array}{l}0,565^{\mathrm{a}} \\
(0,140)\end{array}$ \\
\hline
\end{tabular}

Notas: a - Estatisticamente significativo a $1 \%$; b - Estatisticamente significativo a $5 \%$; c - Estatisticamente significativo a 10\%. Obs: i) Erros padrão robustos entre parênteses; ii) Variáveis contínuas em logaritmo. 
Em geral, os coeficientes obtidos para as variáveis de controle também apresentaram os sinais esperados. As elasticidades da densidade demográfica em relação à despesa per capita foram negativas, possivelmente por economias de escala na provisão de bens públicos. Os coeficientes da variável capital apresentaram sinais positivos, em torno de um, para todas as estimações, indicando que as despesas per capita em capitais são praticamente o dobro das verificadas nos demais municípios. Os coeficientes da variável tx_ocup_domic, referente à proporção empregada de pessoas com mais de 18 anos no domicílio, apresentaram sinais negativos, indicando que uma maior taxa de ocupação nos domicílios está associada a menores gastos per capita. Os coeficientes negativos da variável res_município sugerem que quanto maior o porcentual de pessoas vivendo no município há mais de cinco anos, menor é o gasto per capita. A escolaridade das pessoas com mais de 25 anos (representada pela variável anos_est_25), como esperado, apresentou um efeito positivo sobre a demanda por bens públicos.

Os coeficientes da variável não_branco, em geral, indicam que uma proporção maior de indivíduos não brancos está associada a um gasto per capita maior. Já uma maior proporção de jovens e idosos (referentes às variáveis idade_65 e idade_17) implica menores gastos per capita. Isso pode se dever ao fato de que, nessas faixas etárias, há uma menor incidência de pessoas em idade ativa e, portanto, menor arrecadação de impostos municipais, o que implica menores gastos.

Os coeficientes, em sua maioria, corroboram os resultados encontrados na literatura que trata da estimação da demanda por serviços públicos. Somente a proporção de idosos e a taxa de ocupação apresentaram sinais contrários aos obtidos por Bergstrom e Goodman (1973). As magnitudes dos coeficientes são também bastante próximas das obtidas por estes autores e por Mendes e Sousa (2006).

De fato, as demandas medianas calculadas por Mendes e Sousa (2006) se baseiam no mesmo conjunto de dados utilizado aqui, mas com diferenças em relação às variáveis de controle consideradas, o que resulta em diferentes estimativas. Isso se reflete no cálculo dos parâmetros de congestionamento. As estimativas desses parâmetros, neste trabalho, para a despesa corrente, foram $0,574,{ }^{25}$ enquanto as estimativas dos autores ficam próximas a 0,7 . Os graus de congestionamento aqui encontrados são, portanto, razoavelmente baixos, o que implica um grau de publicidade dos bens mais alto comparativamente aos resultados encontrados tanto por Bergstrom e Goodman (1973) quanto por Mendes e Sousa (2006).

25 O desvio padrão desse parâmetro foi calculado pelo "Método Delta", permitindo obter seu p-valor. 
A classificação proposta por Oxley e Martin (1991, apud SANZ; VELÁZQUEZ, 2002, p. 24) dos grupos de despesa de acordo com as características dos bens, apresentada anteriormente, não revelou grandes disparidades. Porém, como era esperado, pode-se verificar que o grupo de bens meritórios apresenta maior congestionamento $(0,619)$, enquanto os parâmetros de bens públicos puros e de bens econômicos mostraram-se menores, ou seja, menos congestionados. Enquanto a estimativa do grau de congestionamento dos bens puros é de 0,443 , a estimativa dos bens econômicos é de $-0,236$, sendo este último estatisticamente não diferente de zero. O esperado era que os bens públicos fossem mais congestionados. Contudo, pode-se notar, no Quadro 1, que a classificação em bens econômicos se refere às despesas ligadas à infraestrutura produtiva do município, as quais possuem características evidentes de bens públicos puros, já que todos se beneficiam desse tipo de gasto.

Por fim, supondo que as demandas foram estimadas consistentemente, pode-se obter os resíduos que, em módulo, fornecem uma medida da magnitude da incapacidade (ou do erro de percepção) dos dirigentes municipais em atender à demanda mediana. Portanto, cada demanda estimada na Tabela 2 produz uma variável mod $\widehat{U}$ diferente - despesa corrente, despesas com bens meritórios, bens públicos puros, bens econômicos e bem-estar. ${ }^{26} \mathrm{Com}$ isso, pode-se verificar se a incapacidade de atender à demanda mediana é mais ou menos punida nas eleições dependendo do tipo de bem público considerado.

A Tabela 4 apresenta os resultados obtidos com as estimações pelo método de seleção de Heckman, cuja variável dependente é Prop00, que se refere à proporção de votos do candidato à reeleição. Na Tabela 5 , encontram-se os resultados obtidos pelo método Probit com seleção, cuja variável dependente, Reel00, indica o status de reeleição em 2000. Em todos os casos, os testes de independência entre as equações principal e de seleção são rejeitados, indicando que os modelos de seleção são mais adequados do que aqueles que desconsideram o problema de autosseleção.

Em relação aos resultados da Tabela 4, em que a proporção de votos dos candidatos à reeleição municipal constitui a variável dependente, foram verificados seus valores preditos com base na estimação de (15), e se estes se encontravam dentro do intervalo unitário. Como mencionado anteriormente, esta é uma crítica comum à utilização de métodos normais para casos em que a variável dependente é uma proporção, os quais, frequentemente, produzem valores estimados fora desse intervalo. No entanto, os valores preditos se situaram dentro do intervalo unitário, ${ }^{27}$ comprovando que os resultados obtidos não devem ser diferentes utilizando mé-

26 Ver as estatísticas descritivas dessas variáveis na Tabela 2.

27 Estes resultados podem ser obtidos mediante requisição aos autores. 
todos normais (como o Modelo de Seleção de Heckman) ou métodos baseados em distribuições mais apropriadas à modelagem de proporções como regressandos (como a distribuição Beta, entre outras).

Em geral, quando significativos, os coeficientes dos modelos de seleção de Heckman (Heckit) e dos modelos Probit com seleção apresentam o mesmo sinal, o que é bastante razoável, dado que a proporção de votos e o fato de o prefeito ter sido reeleito ou não estão intimamente relacionados. Primeiramente, os resultados obtidos para cada variável explicativa dos modelos são analisados em detalhe para, em seguida, concluir com a análise do impacto das variáveis de interesse referentes ao desvio em relação à demanda mediana.

A variável Prop96 mede o desempenho do prefeito na eleição de 1996, momento em que foi eleito, ou seja, tenta medir o "patrimônio" de votos construído na eleição anterior. Os coeficientes positivos e significativos, referentes a essa variável, estão de acordo com a hipótese, defendida pela literatura, de que há eleitores fiéis a um partido ou candidato, independentemente do desempenho deste durante seu mandato, e que tais eleitores formariam o "estoque inicial" de votos com o qual o político contaria na campanha pela reeleição (PELTZMAN, 1992; MENDES; ROCHA, 2004) - ou seja, quanto maior a proporção de votos obtidos na primeira eleição (1996), maior a probabilidade de candidatura, maior a probabilidade de reeleição e maior a proporção de votos obtidos na próxima eleição (em 2000).

Partido_presidente, Partido_adv_presidente, Partido_governadore Partido_adv_governador são variáveis que buscam captar o impacto de o candidato ser ou não correligionário do presidente ou do governador sobre o resultado eleitoral na reeleição disputada. O fato de ser do mesmo partido do presidente ou do governador, além da transferência da popularidade destes para o prefeito, poderia facilitar o acesso a recursos federais ou estaduais, aumentando os gastos públicos, sem uma pressão por arrecadação, o que impactaria sobre o desempenho na reeleição. O contrário ocorreria para os adversários do presidente ou do governador.

No caso do apoio presidencial, os resultados indicam que o fato de pertencer ao partido do presidente tem efeitos positivos sobre a probabilidade de reeleição. Esse resultado pode ser observado nas estimações por meio do método Probit com Seleção (Tabela 5). Os resultados para o modelo Heckit, no entanto, não são significativos (Tabela 4). Por outro lado, enfrentar um candidato apoiado pelo presidente diminui a proporção de votos obtidos e a probabilidade de reeleição - coeficientes da variável Partido_adv_presidente são negativos e significativos nos dois modelos. 
Tabela 4 - Resultados das Estimações do Modelo de Seleção de Heckman

\begin{tabular}{|c|c|c|c|c|c|c|c|c|c|c|}
\hline & \multicolumn{2}{|c|}{ I } & \multicolumn{2}{|c|}{ II } & \multicolumn{2}{|c|}{ III } & \multicolumn{2}{|c|}{ IV } & \multicolumn{2}{|c|}{ V } \\
\hline & Prop00 & Cand00 & Prop00 & Cand00 & Prop00 & Cand00 & Prop00 & Cand00 & Prop00 & Cand00 \\
\hline \multirow{2}{*}{ Prop96 } & $0,502^{\mathrm{a}}$ & $0,335^{\mathrm{a}}$ & $0,502^{a}$ & $0,332^{\mathrm{a}}$ & $0,502^{\mathrm{a}}$ & $0.339^{a}$ & $0.508^{\mathrm{a}}$ & $0.334^{a}$ & $0.510^{a}$ & $0.324^{a}$ \\
\hline & $(0,038)$ & $(0,105)$ & $(0,038)$ & $(0,105)$ & $(0,038)$ & $(0.105)$ & $(0.038)$ & $(0.106)$ & $(0.038)$ & $(0.106)$ \\
\hline \multirow{2}{*}{ Partido_presidente } & $-0,020$ & $0,126^{\mathrm{b}}$ & $-0,019$ & $0,125^{\mathrm{b}}$ & $-0,019$ & $0.127^{b}$ & -0.020 & $0.134^{\mathrm{b}}$ & -0.018 & $0.116^{\mathrm{b}}$ \\
\hline & $(0,017)$ & $(0,055)$ & $(0,017)$ & $(0,055)$ & $(0,017)$ & $(0.055)$ & $(0.017)$ & $(0.056)$ & $(0.017)$ & $(0.056)$ \\
\hline \multirow{2}{*}{$\begin{array}{l}\text { Partido_adv } \\
\text { presidente }\end{array}$} & $-0,123^{\mathrm{a}}$ & $-0,292^{\mathrm{a}}$ & $-0,123^{\mathrm{a}}$ & $-0,291^{\mathrm{a}}$ & $-0,124^{a}$ & $-0.293^{\mathrm{a}}$ & $-0.125^{\mathrm{a}}$ & $-0.286^{\mathrm{a}}$ & $-0.125^{\mathrm{a}}$ & $-0.292^{\mathrm{a}}$ \\
\hline & $(0,018)$ & $(0,049)$ & $(0,018)$ & $(0,049)$ & $(0,018)$ & $(0.049)$ & $(0.018)$ & $(0.050)$ & $(0.018)$ & $(0.050)$ \\
\hline \multirow{2}{*}{ Partido_governador } & $0,053^{\mathrm{a}}$ & $0,200^{\mathrm{a}}$ & $0,053^{\mathrm{a}}$ & $0,200^{\mathrm{a}}$ & $0,053^{\mathrm{a}}$ & $0.198^{\mathrm{a}}$ & $0.053^{\mathrm{a}}$ & $0.199^{\mathrm{a}}$ & $0.056^{\mathrm{a}}$ & $0.211^{\mathrm{a}}$ \\
\hline & $(0,015)$ & $(0,049)$ & $(0,015)$ & $(0,049)$ & $(0,015)$ & $(0.049)$ & $(0.015)$ & $(0.050)$ & $(0.015)$ & $(0.050)$ \\
\hline \multirow{2}{*}{$\begin{array}{l}\text { Partido_adv } \\
\text { governador }\end{array}$} & $0,033^{\mathrm{c}}$ & $-0,206^{\mathrm{a}}$ & $0,033^{c}$ & $-0,207^{\mathrm{a}}$ & $0,034^{c}$ & $-0.206^{\mathrm{a}}$ & 0.030 & $-0.207^{\mathrm{a}}$ & $0.034^{c}$ & $-0.209^{\mathrm{a}}$ \\
\hline & $(0,020)$ & $(0,053)$ & $(0,020)$ & $(0,053)$ & $(0,020)$ & $(0.053)$ & $(0.020)$ & $(0.053)$ & $(0.020)$ & $(0.053)$ \\
\hline \multirow[b]{2}{*}{ Município_novo } & $0,134^{a}$ & $0,619^{\mathrm{a}}$ & $0,133^{\mathrm{a}}$ & $0,620^{\mathrm{a}}$ & $0,131^{\mathrm{a}}$ & $0.616^{\mathrm{a}}$ & $0.133^{\mathrm{a}}$ & $0.608^{\mathrm{a}}$ & $0.130^{\mathrm{a}}$ & $0.629^{\mathrm{a}}$ \\
\hline & $(0,022)$ & $(0,083)$ & $(0,022)$ & $(0,083)$ & $(0,022)$ & $(0.083)$ & $(0.022)$ & $(0.084)$ & $(0.022)$ & $(0.084)$ \\
\hline \multirow{2}{*}{$\begin{array}{l}\text { Reeleitos } \\
\text { microrregião }\end{array}$} & $0,006^{a}$ & 0,000 & $0,006^{\mathrm{a}}$ & 0,000 & $0,006^{\mathrm{a}}$ & 0.000 & $0.006^{\mathrm{a}}$ & 0.000 & $0.006^{\mathrm{a}}$ & 0.000 \\
\hline & $(0,000)$ & $(0,002)$ & $(0,000)$ & $(0,002)$ & $(0,000)$ & $(0.002)$ & $(0.000)$ & $(0.002)$ & $(0.000)$ & $(0.002)$ \\
\hline \multirow{2}{*}{ Idade_média00 } & $0,264^{\mathrm{a}}$ & $0,537^{\mathrm{a}}$ & $0,264^{\mathrm{a}}$ & $0,535^{\mathrm{a}}$ & $0,267^{a}$ & $0.538^{\mathrm{a}}$ & $0.256^{\mathrm{a}}$ & $0.528^{\mathrm{a}}$ & $0.252^{\mathrm{a}}$ & $0.549^{\mathrm{a}}$ \\
\hline & $(0,064)$ & $(0,144)$ & $(0,064)$ & $(0,144)$ & $(0,064)$ & $(0.144)$ & $(0.064)$ & $(0.145)$ & $(0.064)$ & $(0.145)$ \\
\hline \multirow{2}{*}{ idade_candidato00 } & $-0,526^{\mathrm{a}}$ & - & $-0,525^{\mathrm{a}}$ & - & $-0,526^{a}$ & - & $-0.527^{\mathrm{a}}$ & - & $-0.519^{\mathrm{a}}$ & -- \\
\hline & $(0,045)$ & - & $(0,045)$ & - & $(0,046)$ & - & $(0.046)$ & - & $(0.046)$ & - \\
\hline \multirow{2}{*}{ Município_dividido } & 0,005 & 0,283 & 0,006 & 0,280 & 0,008 & 0.283 & 0.006 & 0.284 & 0.010 & 0.263 \\
\hline & $(0,069)$ & $(0,204)$ & $(0,069)$ & $(0,204)$ & $(0,069)$ & $(0.204)$ & $(0.069)$ & $(0.204)$ & $(0.071)$ & $(0.206)$ \\
\hline \multirow{2}{*}{ Competição } & $-0,046^{\mathrm{a}}$ & $0,142^{\mathrm{a}}$ & $-0,046^{\mathrm{a}}$ & $0,143^{\mathrm{a}}$ & $-0,048^{a}$ & $0.137^{\mathrm{a}}$ & $-0.042^{a}$ & $0.148^{\mathrm{a}}$ & $-0.050^{\mathrm{a}}$ & $0.134^{\mathrm{a}}$ \\
\hline & $(0,016)$ & $(0,048)$ & $(0,016)$ & $(0,048)$ & $(0,016)$ & $(0.048)$ & $(0.016)$ & $(0.049)$ & $(0.016)$ & $(0.049)$ \\
\hline \multirow{2}{*}{ Fracionalização } & $-0,100^{b}$ & $-0,082$ & $-0,099^{\mathrm{b}}$ & $-0,082$ & $-0,097^{b}$ & -0.080 & $-0.097^{b}$ & -0.101 & $-0.097^{b}$ & -0.069 \\
\hline & $(0,042)$ & $(0,127)$ & $(0,042)$ & $(0,127)$ & $(0,042)$ & $(0.127)$ & $(0.042)$ & $(0.128)$ & (0.042) & $(0.128)$ \\
\hline \multirow{2}{*}{$\begin{array}{l}\text { Candidato_reel_ } \\
\text { microrr }\end{array}$} & - & $0,030^{\mathrm{a}}$ & - & $0,030^{\mathrm{a}}$ & - & $0.030^{\mathrm{a}}$ & - & $0.030^{\mathrm{a}}$ & - & $0.030^{\mathrm{a}}$ \\
\hline & - & $(0,002)$ & - & $(0,002)$ & - & $(0.002)$ & - & $(0.002)$ & - & $(0.002)$ \\
\hline \multirow{2}{*}{$\bmod \widehat{U}_{-} D e s p \_c o r r$} & $-0,048^{6}$ & $-0,043$ & - & - & - & - & - & - & - & - \\
\hline & $(0,020)$ & $(0,058)$ & - & & - & - & - & - & 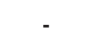 & - \\
\hline \multirow[b]{2}{*}{ mod $\widehat{U} \_$Desp_merit } & - & - & $-0,044^{b}$ & $-0,066$ & - & - & - & $\begin{array}{l}- \\
-\end{array}$ & - & - \\
\hline & - & - & $(0,019)$ & $(0,056)$ & & - & - & - & & - \\
\hline \multirow{2}{*}{$\begin{array}{l}\text { modU_Desp } \\
\text { bens_puros }\end{array}$} & $\cdot$ & - & - & $\begin{array}{r}- \\
-\end{array}$ & $-0,021$ & 0.019 & - & 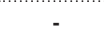 & -. & - \\
\hline & - & - & - & - & $(0,017)$ & $(0.050)$ & - & 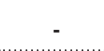 & . & - \\
\hline$\widehat{N U}$ & - & - & - & . & - & . & $-0.038^{\mathrm{a}}$ & -0.005 & - & - \\
\hline modU_bens_econ & - & - & - & . & - & - & $(0.010)$ & $(0.030)$ & - & - \\
\hline & - & - & - & 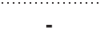 & - & 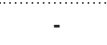 & - & - & -0.008 & 0.012 \\
\hline modU_bem_estar & . & - & . & & 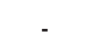 & - & - & - & $(0.011)$ & $(0.035)$ \\
\hline & 0,279 & $-3,633^{\mathrm{a}}$ & 0,281 & $-3,621^{a}$ & 0,273 & $-3.645^{\mathrm{a}}$ & $0.327^{\circ}$ & $-3.623^{\mathrm{a}}$ & 0.308 & $-3.686^{\mathrm{a}}$ \\
\hline nte & $(0,197)$ & $(0,567)$ & $(0,197)$ & $(0,567)$ & $(0,197)$ & $(0.567)$ & $(0.198)$ & $(0.570)$ & $(0.198)$ & $(0.572)$ \\
\hline Razão & & $67^{\mathrm{a}}$ & 0,0 & $67^{a}$ & & $68^{\mathrm{a}}$ & & $68^{\mathrm{a}}$ & & $68^{\mathrm{a}}$ \\
\hline Inversa & & 16 & 00 & 16 & & 16 & & 16 & & 016 \\
\hline N Total & & 75 & 4.9 & & & 974 & & 20 & & 907 \\
\hline $\mathrm{N}$ Censurados & & 70 & 1.6 & & & 670 & & 354 & & 647 \\
\hline $\begin{array}{l}\text { Teste Indep. entre } \\
\text { Eqs. }\left(p>\chi^{2}\right)\end{array}$ & & 00 & 0,0 & & & 000 & & 000 & & 000 \\
\hline
\end{tabular}

Notas: a - Estatisticamente significativo a $1 \%$; b - Estatisticamente significativo a $5 \%$; c - Estatisticamente significativo a 10\%. Obs: i) Erros padrão robustos entre parênteses; ii) Variáveis contínuas em logaritmo. 
Tabela 5 - Resultados das Estimações do Modelo Probit com Seleção

\begin{tabular}{|c|c|c|c|c|c|c|c|c|c|c|}
\hline & \multicolumn{2}{|c|}{1} & \multicolumn{2}{|c|}{ II } & \multicolumn{2}{|c|}{ III } & \multicolumn{2}{|c|}{ IV } & \multicolumn{2}{|c|}{ V } \\
\hline & Reel00 & Cand00 & Reel00 & Cand00 & Reel00 & Cand00 & Reel00 & Cand00 & Reel00 & Cand00 \\
\hline \multirow{2}{*}{ Proporção_votos_96 } & $0,951^{\mathrm{a}}$ & $0,352^{\mathrm{a}}$ & $0,950^{\mathrm{a}}$ & $0,349^{a}$ & $0,953^{\mathrm{a}}$ & $0.355^{\mathrm{a}}$ & $0.958^{\mathrm{a}}$ & $0.353^{\mathrm{a}}$ & $0.954^{\mathrm{a}}$ & $0.345^{\mathrm{a}}$ \\
\hline & $(0,114)$ & $(0,105)$ & $(0,115)$ & $(0,105)$ & $(0,114)$ & $(0.104)$ & $(0.115)$ & $(0.105)$ & $(0.116)$ & $(0.105)$ \\
\hline \multirow{2}{*}{ Partido_presidente } & $0,094^{\circ}$ & $0,107^{\mathrm{b}}$ & $0,094^{\circ}$ & $0,106^{c}$ & $0,097^{c}$ & $0.108^{\mathrm{b}}$ & $0.095^{\mathrm{C}}$ & $0.112^{\mathrm{b}}$ & 0.085 & $0.097^{c}$ \\
\hline & $(0,052)$ & $(0,054)$ & $(0,052)$ & $(0,054)$ & $(0,052)$ & $(0.054)$ & $(0.052)$ & $(0.054)$ & $(0.053)$ & $(0.054)$ \\
\hline \multirow{2}{*}{$\begin{array}{l}\text { Partido_adversá- } \\
\text { rio_presidente }\end{array}$} & $-0,267^{\mathrm{a}}$ & $-0,279^{\mathrm{a}}$ & $-0,266^{a}$ & $-0,280^{a}$ & $-0,266^{a}$ & $-0.280^{\mathrm{a}}$ & $-0.268^{\mathrm{a}}$ & $-0.274^{\mathrm{a}}$ & $-0.269^{a}$ & $-0.280^{\mathrm{a}}$ \\
\hline & $(0,051)$ & $(0,048)$ & $(0,051)$ & $(0,048)$ & $(0,051)$ & $(0.048)$ & $(0.051)$ & $(0.048)$ & $(0.051)$ & $(0.049)$ \\
\hline \multirow{2}{*}{ Partido_governador } & $0,122^{\mathrm{a}}$ & $0,193^{\mathrm{a}}$ & $0,122^{a}$ & $0,194^{\mathrm{a}}$ & $0,122^{a}$ & $0.192^{\mathrm{a}}$ & $0.119^{b}$ & $0.192^{\mathrm{a}}$ & $0.132^{\mathrm{a}}$ & $0.204^{\mathrm{a}}$ \\
\hline & $(0,046)$ & $(0,048)$ & $(0,046)$ & $(0,048)$ & $(0,046)$ & $(0.048)$ & $(0.047)$ & $(0.048)$ & $(0.047)$ & $(0.049)$ \\
\hline \multirow{2}{*}{$\begin{array}{l}\text { Partido_adversá- } \\
\text { rio_govern }\end{array}$} & $-0,049$ & $-0,197^{\mathrm{a}}$ & $-0,049$ & $-0,198^{\mathrm{a}}$ & $-0,049$ & $-0.197^{\mathrm{a}}$ & -0.056 & $-0.198^{\mathrm{a}}$ & -0.040 & $-0.202^{\mathrm{a}}$ \\
\hline & $(0,057)$ & $(0,052)$ & $(0,057)$ & $(0,052)$ & $(0,056)$ & $(0.052)$ & $(0.057)$ & $(0.052)$ & $(0.057)$ & $(0.053)$ \\
\hline \multirow{2}{*}{ Município_novo } & $0,616^{\mathrm{a}}$ & $0,615^{\mathrm{a}}$ & $0,617^{a}$ & $0,616^{\mathrm{a}}$ & $0,614^{a}$ & $0.612^{\mathrm{a}}$ & $0.623^{\mathrm{a}}$ & $0.608^{\mathrm{a}}$ & $0.618^{\mathrm{a}}$ & $0.622^{\mathrm{a}}$ \\
\hline & $(0,071)$ & $(0,081)$ & $(0,071)$ & $(0,081)$ & $(0,071)$ & $(0.080)$ & $(0.072)$ & $(0.081)$ & $(0.072)$ & $(0.081)$ \\
\hline \multirow{2}{*}{$\begin{array}{l}\text { Reeleitos } \\
\text { microrregião }\end{array}$} & $0,029^{\mathrm{a}}$ & 0,000 & $0,029^{a}$ & 0,000 & $0,029^{a}$ & 0.000 & $0.029^{\mathrm{a}}$ & 0.000 & $0.029^{\mathrm{a}}$ & 0.000 \\
\hline & $(0,001)$ & $(0,001)$ & $(0,001)$ & $(0,001)$ & $(0,001)$ & $(0.001)$ & $(0.001)$ & $(0.001)$ & $(0.001)$ & $(0.001)$ \\
\hline \multirow{2}{*}{ Idade_média00 } & $0,607^{\mathrm{a}}$ & $0,531^{\mathrm{a}}$ & $0,607^{\mathrm{a}}$ & $0,530^{\mathrm{a}}$ & $0,603^{a}$ & $0.532^{\mathrm{a}}$ & $0.588^{\mathrm{a}}$ & $0.517^{\mathrm{a}}$ & $0.592^{\mathrm{a}}$ & $0.542^{\mathrm{a}}$ \\
\hline & $(0,178)$ & $(0,141)$ & $(0,178)$ & $(0,141)$ & $(0,177)$ & $(0.140)$ & $(0.179)$ & $(0.141)$ & $(0.179)$ & $(0.142)$ \\
\hline \multirow{2}{*}{ idade_candidato 00} & $-1,013^{\mathrm{a}}$ & & $-1,015^{\mathrm{a}}$ & & $-1,008^{\mathrm{a}}$ & & $-1.007^{\mathrm{a}}$ & & $-0.995^{\mathrm{a}}$ & \\
\hline & $(0,127)$ & & $(0,127)$ & & $(0,127)$ & & $(0.128)$ & & $(0.128)$ & \\
\hline \multirow{2}{*}{ Município_dividido } & 0,054 & 0,287 & 0,052 & 0,284 & 0,052 & 0.288 & 0.055 & 0.290 & 0.070 & 0.270 \\
\hline & $(0,216)$ & $(0,203)$ & $(0,216)$ & $(0,203)$ & $(0,215)$ & $(0.203)$ & $(0.216)$ & $(0.203)$ & $(0.217)$ & $(0.205)$ \\
\hline \multirow{2}{*}{ Competição } & $0,188^{\mathrm{a}}$ & $0,120^{\mathrm{b}}$ & $0,189^{\mathrm{a}}$ & $0,121^{b}$ & $0,184^{a}$ & $0.116^{\mathrm{b}}$ & $0.196^{\mathrm{a}}$ & $0.126^{\mathrm{a}}$ & $0.181^{\mathrm{a}}$ & $0.110^{\mathrm{b}}$ \\
\hline & $(0,048)$ & $(0,047)$ & $(0,047)$ & $(0,047)$ & $(0,047)$ & $(0.047)$ & $(0.048)$ & $(0.047)$ & $(0.048)$ & $(0.047)$ \\
\hline \multirow{2}{*}{ Fracionalização } & $-0,204$ & $-0,095$ & $-0,205$ & $-0,095$ & $-0,202$ & -0.094 & -0.204 & -0.109 & -0.183 & -0.081 \\
\hline & $(0,129)$ & $(0,126)$ & $(0,129)$ & $(0,126)$ & $(0,129)$ & $(0.126)$ & $(0.130)$ & $(0.127)$ & $(0.130)$ & $(0.127)$ \\
\hline \multirow{2}{*}{$\begin{array}{l}\text { Candidato_reel } \\
\text { microrregião }\end{array}$} & & $0,030^{\mathrm{a}}$ & & $0,030^{\mathrm{a}}$ & & $0.030^{\mathrm{a}}$ & & $0.030^{\mathrm{a}}$ & & $0.030^{\mathrm{a}}$ \\
\hline & & $(0,001)$ & & $(0,001)$ & & $(0.001)$ & & $(0.001)$ & & $(0.001)$ \\
\hline \multirow{2}{*}{ mod $\widehat{U}_{-}$Desp_corr } & $-0,013$ & $-0,053$ & & & & & & & & \\
\hline & $(0,056)$ & $(0,053)$ & & & & & & & & \\
\hline modU_Desp_merit & & & $\begin{array}{l}-0,031 \\
(0,055)\end{array}$ & $\begin{array}{l}-0,072 \\
(0,052)\end{array}$ & & & & & & \\
\hline \multirow{2}{*}{$\begin{array}{l}\text { modU__Desp_bens } \\
\text { puros }\end{array}$} & & & & & 0,038 & -0.002 & & & & \\
\hline & & & & & & & & & & \\
\hline mod $\widehat{U}_{-}$bens_econ & & & & & & & $\begin{array}{l}-0.027 \\
(0.030)\end{array}$ & $\begin{array}{l}-0.019 \\
(0.029)\end{array}$ & & \\
\hline mod $\widehat{U} \_b e m \_e s t a r$ & & & & & & & & & $\begin{array}{l}-0.005 \\
(0.034)\end{array}$ & $\begin{array}{l}0.010 \\
(0.034)\end{array}$ \\
\hline & 0,415 & & & $-3,531^{a}$ & & $-3.541^{\mathrm{a}}$ & & $-3.501^{\mathrm{a}}$ & 0.419 & $-3.584^{\mathrm{a}}$ \\
\hline Constante & $(0,594)$ & $(0,555)$ & $(0,594)$ & $(0,555)$ & $(0,593)$ & $(0.555)$ & $(0.599)$ & $(0.558)$ & $(0.598)$ & $(0.559)$ \\
\hline Razão de Mills & & $67^{\mathrm{a}}$ & & $67^{\mathrm{a}}$ & & $68^{a}$ & & $68^{a}$ & & $68^{a}$ \\
\hline Inversa & & 16 & & 016 & & 016 & & 16 & & 016 \\
\hline N Total & & 51 & & 951 & & 950 & & 396 & & 883 \\
\hline N Censurados & & & & 670 & & 670 & & 654 & & 647 \\
\hline $\begin{array}{l}\text { Teste Indep, entre } \\
\text { Eqs, }\left(p>\chi^{2}\right)\end{array}$ & & 00 & & 000 & & 000 & & 000 & & 000 \\
\hline
\end{tabular}

Notas: a - Estatisticamente significativo a $1 \%$; b - Estatisticamente significativo a $5 \%$; c - Estatisticamente significativo a 10\%. Obs: i) Erros padrão robustos entre parênteses; ii) Variáveis contínuas em logaritmo. 
No caso do apoio dos governadores, os resultados da Tabela 4 mostram que candidatos à reeleição, tanto do partido do governador quanto de partidos rivais (que haviam conseguido a segunda maior proporção de votos na eleição para governador ocorrida em 1998), conseguem uma maior proporção de votos do que os demais.

De acordo com Mendes e Rocha (2004), indivíduos que lideram movimentos emancipacionistas bem-sucedidos passam a usufruir de grande prestígio político, o que poderia viabilizar sua candidatura e eleição como prefeito, assim como sua posterior reeleição. Além disso, um município novo "não possui dívidas ou problemas herdados do passado, já nasce com transferências federais garantidas e pode agradar um grande número de eleitores ao realizar obras para instalar a nova prefeitura, a câmara de vereadores e ao contratar novos funcionários municipais" (p. 23). Os coeficientes positivos e significativos da variável Município_novo, nas duas equações (principais e de seleção), tanto usando o modelo de Heckman (Tabela 4) quanto usando o modelo Probit com seleção (Tabela 5), reforçam essa hipótese.

Por outro lado, "é possível que os prefeitos de municípios que perderam parte de seus territórios, em função da emancipação de distritos que se transformaram em novos municípios, tenham perdido prestígio político" (MENDES; ROCHA, 2004, p. 23). Ou seja, prefeitos de municípios divididos teriam uma menor probabilidade de se candidatarem, uma menor proporção de votos e uma menor probabilidade de reeleição. Os resultados obtidos, contudo, não confirmam essa hipótese. Os coeficientes da variável Município_dividido não são significativos nas equações principais e de seleção, tanto quando se estima seu efeito sobre a proporção de votos (Tabela 4) quanto sobre a probabilidade de reeleição (Tabela 5).

As variáveis Reeleitos_microrregião e Candidato_reel_microrr - sendo esta variável aquela excluída das equações de interesse (15) e (18) e incluída nas de seleção (16) e (19) - buscam captar a influência de fatores comuns aos municípios vizinhos sobre cada um dos municípios - por exemplo, "uma microrregião que esteja sofrendo uma crise na economia local tenderia a ter um porcentual menor de reeleição, enquanto outra região, onde houve um grande investimento federal, poderia apresentar índices mais elevados de reeleição" (MENDES; ROCHA, 2004, p. 22). Assim, quanto maior a proporção de candidatos à reeleição na microrregião, maior seria a probabilidade de um prefeito também se candidatar e, quanto maior a proporção de prefeitos reeleitos, maior seria a proporção de votos obtidos por este e maior seria sua probabilidade de reeleição. Os coeficientes positivos e significativos dessas variáveis, usando Heckit e Probit com seleção, corroboram essa hipótese.

Os coeficientes das variáveis competição e fracionalização foram negativos e significativos, como esperado. Uma maior fracionalização partidária no legislativo 
está positivamente associada a uma maior divisão das preferências do eleitorado, o que reduz a proporção de votos recebido por cada candidato e a probabilidade de reeleição. Da mesma forma, quanto mais candidatos concorrem no pleito, menor tende a ser a proporção recebida de votos, mesmo quando se incluem alternativas irrelevantes.

Por fim, o coeficiente da variável mod $\widehat{U} \_$Desp_corr, no modelo I da Tabela 4, cuja variável dependente é a proporção de votos, apresenta sinal negativo e significativo a 5\%. Esse resultado é favorável ao modelo do eleitor mediano, pois indica que erros de percepção ou desvios em relação à demanda mediana diminuem a proporção de votos dos candidatos à reeleição. Se as variáveis de interesse forem medidas com erro, esses resultados podem estar, inclusive, atenuados, subestimando a magnitude do efeito. Quando considerados os desvios da demanda mediana por diferentes tipos de bens, verifica-se um coeficiente negativo e significativo a $5 \%$ para a variável mod $\widehat{U} \_$Desp_merit (modelo II da Tabela 4), e para a variável mod $\widehat{U} \_b e n s \_e c o n$, (modelo IV da Tabela 4). Os coeficientes das variáveis mod $\widehat{U} \_D e s p \_b e n s \_p u r o s$ e mod $\widehat{U} \_$bem_estar (modelos III e V da Tabela 4) são negativos, porém não significativos aos níveis convencionais, mas, como mencionado anteriormente, podem sofrer atenuação devido a erro de mensuração.

Os coeficientes das variáveis de interesse, quando se usa o método Probit com seleção, são todos negativos (exceto para a variável mod $\widehat{U} \_$Desp_bens_puros), porém, em nenhum caso, estatisticamente significativos a $10 \%$.

Foi realizado um teste de robustez que consistiu em estimar as demandas medianas sem usar variáveis de controle para estimar as variáveis mod $\widehat{U}$ para cada grupo de despesas. Os coeficientes dessas variáveis estimadas pelo modelo em (15), em que a variável dependente é a proporção de votos em 2000, também se revelaram negativos e significativos, indicando que o modelo é robusto à inclusão de controles. ${ }^{28}$ Já os coeficientes das variáveis estimadas pelo modelo (18) (Probit com seleção), também se revelaram não significativos.

Portanto, nos modelos em que o desempenho eleitoral é medido pela proporção de votos ao invés do status de reeleito ou não, os coeficientes das variáveis de interesse são negativos e significativos, indicando que o modelo do eleitor mediano é válido em alguma medida. $\mathrm{O}$ fato de o mesmo resultado não se verificar, quando a

28 O coeficiente da variável mod $\widehat{U} \_$Desp_corr estimada sem controles sobre a proporção de votos foi igual -0.047 com erro padrão de $0,01 \overline{9}$. O coeficiente da variável mod $\widehat{U} \_$Desp_merit foi de -0.046 com erro padrão de 0,019 e o coeficiente da variável mod $\widehat{U}$ bens econ foi igual a -0.040 com erro padrão igual a 0,010 . Todos esses coeficientes são significativos a $5 \%$. Os coeficientes das demais variáveis de desvio da demanda mediana foram negativos, mas não foram significativos. Os resultados completos dessas estimações podem ser obtidos sob requisição aos autores. 
variável dependente é binária, pode estar ligado tanto à possibilidade de atenuação dos coeficientes quanto ao fato de que há maior variação no caso em que a variável é contínua.

\section{Considerações Finais}

Neste trabalho, buscou-se testar o Modelo do Eleitor Mediano para o caso dos municípios brasileiros. De acordo com esse modelo, quanto mais distante a cesta efetivamente ofertada estiver da demanda mediana, menores devem ser as chances de o candidato se reeleger. Assim, para a realização do teste empírico, foi necessário, em primeiro lugar, estimar a demanda do eleitor mediano por bens públicos. A estimação dessa demanda se baseou na hipótese de que os dirigentes municipais não têm informação perfeita, ou seja, cometem erros não sistemáticos em suas previsões (expectativas) sobre a verdadeira demanda mediana. Como a "Emenda da Reeleição" permitiu, a partir de 1998, que o presidente, prefeitos e governadores, concorressem à eleição, pôde-se mensurar a cesta ofertada desses candidatos como sendo idêntica ao gasto efetivamente observado no ano de 2000, quando ocorreram as eleições. Com isso, foi possível estimar uma medida do tamanho do erro de percepção dos candidatos à reeleição em relação à demanda do eleitor mediano.

Para que o teste fosse válido, pelo menos uma de duas suposições deveria ser verificada em relação à medida de erro de percepção $(\bmod \widehat{U})$. Uma delas é que o resíduo estimado da demanda é puramente fruto de erros de percepção, o que é consideravelmente forte. A outra, é que $\bmod \widehat{U}$ possa ser considerada uma variável medida com erro.

Se a primeira hipótese se verifica, as estimativas do impacto da variável mod $\widehat{U}$ sobre a proporção de votos e a probabilidade de reeleição, utilizando os modelos de seleção de Heckman (Heckit) e Probit com seleção, são consistentes. Se, por outro lado, a variável mod $\widehat{U}$ puder ser considerada como medida com erro, os coeficientes serão "atenuados" (viesados em direção a zero). Isso, apesar de não ser o melhor dos cenários, não invalida os resultados, pois coeficientes significativos dão o sinal correto para as estimações. Portanto, se o interesse residir somente na direção, como é o caso deste trabalho, é possível obter conclusões válidas das estimações.

Os resultados encontrados neste trabalho, com base em dados municipais do Censo Populacional do IBGE e do TSE referentes ao ano de 2000, validaram o Modelo do Eleitor Mediano para o caso dos municípios brasileiros. Verificou-se que um aumento na magnitude do erro de percepção dos dirigentes municipais, candidatos à reeleição, em relação à cesta mediana demandada, tem um impacto negativo so- 
bre a proporção de votos recebidos pelo candidato, o que é exatamente a ideia do modelo do eleitor mediano. Por outro lado, os resultados referentes à probabilidade de reeleição, utilizando o método Probit com seleção, não foram significativos. Considerando diferentes grupos de bens, verificou-se que desvios em relação à demanda mediana por bens meritórios e bens econômicos são mais severamente punidos pelos eleitores do que desvios em relação à demanda mediana por outros grupos de bens.

\section{Referências}

ABENSUR, T. C.; CRIBARI-NETO, F.; MENEZES, T. A. Impactos do Programa Bolsa Família nos resultados das eleições presidenciais no Brasil em 2006. In: ENCONTRO NACIONAL DE ECONOMIA, 35, 2007, Recife. Anais... Recife: ANPEC, 2007.

BLACK, D. On the Rationale of Group Decision-making. The Journal of Political Economy, v. 56, n. 1, p. 23-34, Feb. 1948,

BERGSTROM, T. C.; GOODMAN, R. P. Private demands for public goods. The American Economic Review, v. 63, n. 3. p. 280-296, June 1973.

BERGSTROM, T. C.; RUBINFELD, D. L.; SHAPIRO, P. Micro-based estimates of demand functions for local school expenditures. Econometrica, v. 50, n. 5, p. 1183-1205, Sept. 1982.

BORCHERDING, T. E.; DEACON, R. T. The demand for the services of nonfederal governments. The American Economic Review, v. 62, n. 5, p. 891-901, Dec. 1972.

BOWEN, $\mathrm{H}$. The interpretation of voting in the allocation of economic resources, Quarterly Journal of Economics, v. 58, n. 1, p. 27-48, Nov. 1943.

CANÊDO-PINHEIRO, M. Bolsa Família ou desempenho da economia? Determinantes da reeleição de Lula em 2006. In: ENCONTRO NACIONAL DE ECONOMIA, 37, 2009, Salvador. Anais... Salvador: ANPEC, 2009.

DOI, T. Empirics of the median voter hypothesis in Japan. Empirical Economics, Springer, v. 24, p. 667-691, Apr. 1999.

DOWNS, A. An economic theory of democracy. New York: Harper, 1957.

EDGERTON, D.; JOCHUMZEN, P. Estimation in binary choice models with measurement errors. Department of Economics, Lund University, Working Papers Series n. 4, p. 1-64, Apr. 2003.

FEREJOHN, J. Incumbent performance and electoral control. Public Choice 50, p. $5-25,1986$.

FERRARI, S. L. P., CRIBARI-NETO, F. Beta regression for modelling rates and proportions. Journal of Applied Statistics, v. 31, n. 1, p. 799-815, 2004. 
GRAMLICH, E. M.; RUBINFELD, D. L. Micro estimates of public spending demand functions and tests of the Tiebout and median voter hypotheses. The Journal of Political Economy, v. 90, n. 3, p. 536-560, Jun. 1982.

HECKMAN, J. J. Sample selection bias as a specification error. Econometrica, v. 47, n. 1 p. 153-161, Jan. 1979.

INMAN, R. P. Testing political economy's 'as if' proposition: is the median income voter really decisive? Public Choice 33, n. 4, p. 45-65, 1978.

KIESCHNICK, R., MCCULLOUGH, B. D. Regression analysis of variates observed on $(0,1)$ : percentages, proportions and fractions. Statistical Modelling, v. 3, p. 193-213, 2003.

KING, G. A solution to the ecological inference problem: reconstructing individual behavior from aggregated data. Princeton: Princeton University Press, 1997.

MENDES, C. C. A demanda por serviços públicos municipais no Brasil: a abordagem do eleitor mediano revisitada. Tese (Doutorado em Economia) - Universidade de Brasília (Unb), Brasília, 2005. 196 fls.

.; SOUSA, M. C. S. Estimando a demanda por serviços públicos nos municípios brasileiros. Revista Brasileira de Economia, v. 60, n. 3, p. 281-296, Jul-Set 2006.

MENDES, M. Federalismo fiscal e crescimento do governo: evidências eleitorais para o Brasil. In: ENCONTRO NACIONAL DE ECONOMIA, 32, 2004, João Pessoa. Anais... João Pessoa: ANPEC, 2004.

.; ROCHA, C. A. A. O que reelege um prefeito? Brasília: Consultoria Legislativa do Senado Federal, Coordenação de Estudos, abr. 2007. (Textos para Discussão n. 7).

MENEGUIN, F. B.; BUGARIN, M. S. Reeleição e Política Fiscal: um Estudo dos Efeitos nos Gastos Públicos, Economia Aplicada 5(3): 600-22, 2001.

.; CARVALHO, A. X. O que leva um governante à reeleição? Brasília: IPEA, nov. 2005. (Texto para Discussão n. 1.135).

NAKAGUMA, M. Y.; BENDER, S. Impactos sobre ciclos politicos e performance fiscal dos estados (1986-2002). In: ENCONTRO NACIONAL DE ECONOMIA, 32, 2004, João Pessoa. Anais... João Pessoa: ANPEC, 2004.

PAOLINO, P. Maximum likelihood estimation of models with beta distributed dependent variables. Political Analysis, v. 9, n. 4, p. 325-346, 2001.

PELTZMAN, S. Voters as fiscal conservatives. The Quarterly Journal of Economics, v. 107, n. 2, p. 327-361, May 1992.

ROGOFF, K.; SILBERT, A. Elections and macroeconomic policy cycles. Review of Economic Studies, v. 55, p. 1-16, 1988.

RUBINFELD, D. L.; SHAPIRO, P.; ROBERTS, J. Tiebout Bias and the demand for local public schooling. The Review of Economics and Statistics, v. 69, n. 3, p. 426-437, Aug 1987. 
SAMUELSON, P. The pure theory of public expenditure.The Review of Economics and Statistics, v. 36, n. 4, p. 387-389, Nov. 1954.

SANZ, I.; VELÁZQUEZ, F. J. Determinants of the composition of government expenditure by functions. European Economy Group Working Papers, n. 13, p. 1-27, Feb. 2002.

SHAPIRO, S. S.; FRANCIA, R. S. An approximate analysis of variance test for normality. Journal of the American Statistical Association, v. 67, p. 215, 1972. 